\title{
Quantification of peroxynitric acid and peroxyacyl nitrates using an ethane-based thermal dissociation peroxy radical chemical amplification cavity ring-down spectrometer
}

\author{
Youssef M. Taha ${ }^{1}$, Matthew T. Saowapon ${ }^{1}$, Faisal V. Assad ${ }^{1}$, Connie Z. Ye $^{1}$, Xining Chen ${ }^{1, a}$, Natasha M. Garner ${ }^{1}$, and \\ Hans D. Osthoff ${ }^{1}$ \\ ${ }^{1}$ Department of Chemistry, University of Calgary, 2500 University Drive N.W., Calgary, Alberta T2N 1N4, Canada \\ anow at: Department of Chemistry, McGill University, 801 Sherbrooke St. West, Montreal, Quebec H3A 2K6, Canada
}

Correspondence: Hans D. Osthoff (hosthoff@ucalgary.ca)

Received: 9 April 2018 - Discussion started: 16 April 2018

Revised: 27 June 2018 - Accepted: 29 June 2018 - Published: 17 July 2018

\begin{abstract}
Peroxy and peroxyacyl nitrates (PNs and PANs) are important trace gas constituents of the troposphere which are challenging to quantify by differential thermal dissociation with $\mathrm{NO}_{2}$ detection in polluted (i.e., high- $\mathrm{NO}_{x}$ ) environments. In this paper, a thermal dissociation peroxy radical chemical amplification cavity ring-down spectrometer (TDPERCA-CRDS) for sensitive and selective quantification of total peroxynitrates $\left(\Sigma \mathrm{PN}=\Sigma \mathrm{RO}_{2} \mathrm{NO}_{2}\right)$ and of total peroxyacyl nitrates $\left(\Sigma \mathrm{PAN}=\Sigma \mathrm{RC}(\mathrm{O}) \mathrm{O}_{2} \mathrm{NO}_{2}\right)$ is described. The instrument features multiple detection channels to monitor the $\mathrm{NO}_{2}$ background and the $\mathrm{RO}_{x}\left(=\mathrm{HO}_{2}+\mathrm{RO}_{2}+\Sigma \mathrm{RO}_{2}\right)$ radicals generated by TD of $\Sigma$ PN and/or $\Sigma$ PAN. Chemical amplification is achieved through the addition of $0.6 \mathrm{ppm}$ $\mathrm{NO}$ and $1.6 \% \mathrm{C}_{2} \mathrm{H}_{6}$ to the inlet. The instrument's performance was evaluated using peroxynitric acid (PNA) and peroxyacetic or peroxypropionic nitric anhydride (PAN or PPN) as representative examples of $\Sigma P N$ and $\Sigma P A N$, respectively, whose abundances were verified by iodide chemical ionization mass spectrometry (CIMS). The amplification factor or chain length increases with temperature up to $69 \pm 5$ and decreases with analyte concentration and relative humidity (RH). At inlet temperatures above 120 and $250^{\circ} \mathrm{C}$, respectively, PNA and $\Sigma$ PAN fully dissociated, though their TD profiles partially overlap. Furthermore, interference from ozone $\left(\mathrm{O}_{3}\right)$ was observed at temperatures above $150^{\circ} \mathrm{C}$, rationalized by its partial dissociation to $\mathrm{O}$ atoms which react with $\mathrm{C}_{2} \mathrm{H}_{6}$ to form $\mathrm{C}_{2} \mathrm{H}_{5}$ and $\mathrm{OH}$ radicals. Quantification of PNA and $\Sigma$ PAN in laboratory-generated mixtures containing $\mathrm{O}_{3}$ was achieved by simultaneously monitoring the TD-PERCA responses in multiple parallel CRDS channels
\end{abstract}

set to different temperatures in the 60 to $130^{\circ} \mathrm{C}$ range. The $(1 \mathrm{~s}, 2 \sigma)$ limit of detection (LOD) of TD-PERCA-CRDS is $6.8 \mathrm{pptv}$ for PNA and $2.6 \mathrm{pptv}$ for $\Sigma$ PAN and significantly lower than TD-CRDS without chemical amplification. The feasibility of TD-PERCA-CRDS for ambient air measurements is discussed.

\section{Introduction}

The $\mathrm{RO}_{x}\left(=\mathrm{OH}+\mathrm{HO}_{2}+\Sigma \mathrm{RO}_{2}\right)$ radicals and the nitrogen oxides $\left(\mathrm{NO}_{x}=\mathrm{NO}+\mathrm{NO}_{2}\right)$ are important trace constituents of the atmosphere that drive diverse processes such as the photochemical production of ozone $\left(\mathrm{O}_{3}\right)$ in the troposphere (Kirchner and Stockwell, 1996; Fleming et al., 2006), the catalytic destruction of $\mathrm{O}_{3}$ in the stratosphere (Bates and Nicolet, 1950; Stenke and Grewe, 2005; Solomon, 1999; Portmann et al., 1999), and the chemistry of organic aerosol formation (Ziemann and Atkinson, 2012; Ehn et al., 2014; Crounse et al., 2013). In the troposphere, the concentrations of these species are frequently buffered by $\mathrm{RO}_{x}$ and $\mathrm{NO}_{x}$ reservoir species, of which peroxynitric acid (PNA, $\mathrm{HO}_{2} \mathrm{NO}_{2}$ ), alkyl peroxy nitrates such as methyl peroxynitrate $\left(\mathrm{CH}_{3} \mathrm{O}_{2} \mathrm{NO}_{2}, \mathrm{MPN}\right)$, and peroxyacyl nitrates (PANs, $\mathrm{RC}(\mathrm{O}) \mathrm{O}_{2} \mathrm{NO}_{2}$ ) are important examples (Singh et al., 1992; Roberts, 1990). Much insight into $\mathrm{RO}_{x}$ and $\mathrm{NO}_{x}$ chemistry has been gained by measuring the atmospheric abundances of these reservoirs. Significant PNA concentrations, for example, have been observed in the polar regions (Slusher et al., 2001; Davis et al., 2004; Jones et al., 2014), aloft in the 
Table 1. Typical ${ }^{\mathrm{a}}$ PNA and PAN mixing ratios in various environments where both were quantified.

\begin{tabular}{llll}
\hline Location & PNA (pptv) & PAN (pptv) & PNA / PAN \\
\hline Antarctica - summer & 20, Slusher et al. (2001) & 15.6, Eisele et al. (2008) & 1.3 \\
Antarctica - summer & 22, Jones et al. (2014) & 15.6, Eisele et al. (2008) & 1.4 \\
Antarctica - summer & 2.5, Jones et al. (2014) & 9.2, Mills et al. (2007) & 0.27 \\
Remote troposphere - spring & - & - & $0.13^{\mathrm{b}}$, \\
& & & Murphy et al. (2004) \\
Free troposphere - summer & 45, Kim et al. (2007) & 280, Singh et al. (2006) & $0.16^{\mathrm{c}}$ \\
Uintah Basin - winter 2013 & 500, Veres et al. (2015) & 2000, Ahmadov et al. (2015) & 0.25 \\
Uintah Basin - winter 2014 & 100, Veres et al. (2015) & 300, Lee et al. (2015) & 0.33 \\
Atlanta - winter & 3.7, D. X. Chen et al. (2017) & 640-800, Lee et al. (2013) & $<0.01$ \\
Atlanta - summer & 11.7, D. X. Chen et al. (2017) & 640-800, Lee et al. (2013) & $0.01-0.02$ \\
\hline
\end{tabular}

\footnotetext{
a Average values.

b Calculated assuming all non-PAN and PPN peroxy nitrate is PNA.

c Averages of data posted on $\mathrm{ftp} / / / \mathrm{ftp}$-air.larc.nasa.gov/pub/INTEXA/DC8_AIRCRAFT/.
}

Table 2. Selected thermal dissociation methods for quantification of daytime $\mathrm{NO}_{y}$ species.

\begin{tabular}{llll}
\hline Species quantified & $\mathrm{NO}_{2}$ detection method & Group & Reference \\
\hline $\mathrm{NO}_{2}, \Sigma$ PAN, $\Sigma$ AN, $\mathrm{HNO}_{3}$ & $\mathrm{LIF}$ & Berkeley & Day et al. (2002) \\
$\Sigma \mathrm{PN}$ & $\mathrm{LIF}$ & Berkeley & Murphy et al. (2004) \\
$\mathrm{HONO}$ & $\mathrm{CL}$ & Berkeley & Perez et al. (2007) \\
$\mathrm{NO}_{2}, \Sigma$ PAN, $\Sigma$ AN & CRDS & Calgary & Paul et al. (2009) \\
Aerosol nitrates & LIF & Berkeley & Rollins et al. (2010) \\
$\mathrm{ClNO}_{2}$ & CRDS & Calgary & Thaler et al. (2011) \\
$\mathrm{NO}_{2}, \Sigma$ PAN, $\Sigma$ AN, $\mathrm{HNO}_{3}$ & LIF & L'Aquila & Di Carlo et al. (2013) \\
$\mathrm{NO}_{2}, \mathrm{NO}_{2}, \mathrm{HONO}, \mathrm{NO}_{y}$, & CRDS & NOAA & Wild et al. (2014); \\
$\mathrm{Ammonium} \mathrm{nitrate}_{\mathrm{NO}_{2}, \Sigma \text { PAN, } \Sigma \text { AN }}$ & CRDS & & Womack et al. (2017) \\
$\mathrm{NO}_{2}, \Sigma$ PAN, $\Sigma$ AN & CAPS & Max Planck Institute & Thieser et al. (2016) \\
$\mathrm{NO}_{2}, \mathrm{RNO}_{2}$ & CRDS & Osaka & Sadanaga et al. (2016) \\
$\Sigma \mathrm{PNN}_{2}, \Sigma$ PAN & PERCA-CRDS & Hefei & J. Chen et al. (2017) \\
\hline
\end{tabular}

free and upper troposphere (Kim et al., 2007; Murphy et al., 2004), in highly polluted environments such as the Uintah Basin in winter (Veres et al., 2015), and in urban atmospheres (Spencer et al., 2009; D. X. Chen et al., 2017) and have given valuable insights into radical budgets at these locations. The PANs and PNA are prone to thermal dissociation (TD), such that higher concentrations are more commonly observed in cold regions, aloft in the free and upper troposphere, or in winter (Table 1). However, their rate of production is greater in summer as the actinic flux intensifies. Mixing ratios of PNA peak in the range from tens to a few hundreds of partsper-trillion by volume (pptv, $10^{-12}$ ) and those of peroxyacetic nitric anhydride $\left(\mathrm{PAN} ; \mathrm{CH}_{3} \mathrm{C}(\mathrm{O}) \mathrm{O}_{2} \mathrm{NO}_{2}\right.$ ) can exceed 10 parts-per-billion by volume (ppbv, $10^{-9}$ ) (Tuazon et al., 1981).

There is ongoing interest to develop improved techniques for quantification of PANs (Roberts, 2007; Wooldridge et al., 2010; Zheng et al., 2011; Tokarek et al., 2014) and PNA (Murphy et al., 2004; Spencer et al., 2009; Veres et al., 2015; D. X. Chen et al., 2017). TD methods (Table 2) such as TD coupled to laser-induced fluorescence (TD-LIF) (Wooldridge et al., 2010; Day et al., 2002; Di Carlo et al., 2013), to cavity ring-down spectroscopy (TD-CRDS) (Paul et al., 2009; Thaler et al., 2011; Paul and Osthoff, 2010; Thieser et al., 2016; Sobanski et al., 2016; Womack et al., 2017), or to cavity phase-shift spectroscopy (TDCAPS) (Sadanaga et al., 2016) detection of $\mathrm{NO}_{2}$ are attractive as they can be used to monitor all components of odd nitrogen $\left(\mathrm{NO}_{y}\right)$ in parallel, including $\mathrm{NO}_{2}$ (inlet operated at ambient temperature), total peroxy nitrates $\left(\Sigma \mathrm{PN}=\mathrm{PNA}+\mathrm{MPN}+\right.$; inlet heated to $\left.\sim 100^{\circ} \mathrm{C}\right)$, total peroxyacyl nitrates $(\Sigma \mathrm{PAN}=\mathrm{PAN}+$ peroxypropinoic nitric anhydride $\left.\left(\mathrm{C}_{2} \mathrm{H}_{5} \mathrm{C}(\mathrm{O}) \mathrm{O}_{2} \mathrm{NO}_{2}+\right) ; \sim 250^{\circ} \mathrm{C}\right)$, total alkyl nitrates $+\mathrm{ClNO}_{2}\left(\Sigma \mathrm{AN} ; \sim 420^{\circ} \mathrm{C}\right)$, and $\mathrm{HNO}_{3}\left(\sim 600^{\circ} \mathrm{C}\right)$, simply by deploying multiple detection channels and setting appropriate inlet temperatures. Molecules such as NO and $\mathrm{HONO}$ can be quantified through the addition of $\mathrm{O}_{3}$ following TD (Wild et al., 2014; Womack et al., 2017; Fuchs et al., 2009). 
Table 3. List of chemical reactions ${ }^{\mathrm{a}}$.

\begin{tabular}{|c|c|c|c|}
\hline Number & Reaction & $k\left(\mathrm{~cm}^{3}\right.$ molecule $\left.{ }^{-1} \mathrm{~s}^{-1}\right)$ & $\begin{array}{l}k_{298 \mathrm{~K}} \\
\left(\mathrm{~cm}^{3} \text { molecule }^{-1} \mathrm{~s}^{-1}\right)\end{array}$ \\
\hline (R1) & $\mathrm{CH}_{3} \mathrm{O}_{2}+\mathrm{NO} \rightarrow \mathrm{CH}_{3} \mathrm{O}+\mathrm{NO}_{2}$ & $2.3 \times 10^{-12} \times \mathrm{e}^{(360 / T)}$ & $7.7 \times 10^{-12}$ \\
\hline (R2) & $\mathrm{CH}_{3} \mathrm{O}+\mathrm{O}_{2} \rightarrow \mathrm{HCHO}+\mathrm{HO}_{2}$ & $7.2 \times 10^{-14} \times \mathrm{e}^{(-1080 / T)}$ & $1.9 \times 10^{-15}$ \\
\hline (R3) & $\mathrm{HO}_{2}+\mathrm{NO} \rightarrow \mathrm{HO}+\mathrm{NO}_{2}$ & $3.5 \times 10^{-12} \times \mathrm{e}^{(270 / T)}$ & $8.5 \times 10^{-12}$ \\
\hline (R4) & $\mathrm{C}_{2} \mathrm{H}_{6}+\mathrm{HO}+\mathrm{O}_{2} \rightarrow \mathrm{H}_{2} \mathrm{O}+\mathrm{C}_{2} \mathrm{H}_{5} \mathrm{O}_{2}$ & $6.9 \times 10^{-12} \times \mathrm{e}^{(-1000 / T)}$ & $2.4 \times 10^{-13}$ \\
\hline (R5) & $\mathrm{C}_{2} \mathrm{H}_{5} \mathrm{O}_{2}+\mathrm{NO} \rightarrow \mathrm{C}_{2} \mathrm{H}_{5} \mathrm{O}+\mathrm{NO}_{2}$ & $2.55 \times 10^{-12} \times \mathrm{e}^{(380 / T)} \times 0.99$ & $9.1 \times 10^{-12}$ \\
\hline (R6) & $\mathrm{C}_{2} \mathrm{H}_{5} \mathrm{O}+\mathrm{O}_{2} \rightarrow \mathrm{CH}_{3} \mathrm{CHO}+\mathrm{HO}_{2}$ & $2.4 \times 10^{-14} \times \mathrm{e}^{(-325 / T)}$ & $8.1 \times 10^{-15}$ \\
\hline (R7) & $\mathrm{PAN} \rightarrow \mathrm{CH}_{3} \mathrm{CO}_{3}+\mathrm{NO}_{2}$ & See Table 4 & $4.4 \times 10^{-4} \mathrm{~s}^{-1}$ \\
\hline (R8) & $\begin{array}{l}\mathrm{CH}_{3} \mathrm{C}(\mathrm{O}) \mathrm{O}_{2}+\mathrm{NO} \rightarrow \mathrm{NO}_{2}+\mathrm{CH}_{3} \mathrm{C}(\mathrm{O}) \mathrm{O} \\
\rightarrow \mathrm{NO}_{2}+\mathrm{CH}_{3}+\mathrm{CO}_{2}\end{array}$ & $7.5 \times 10^{-12} \times \mathrm{e}^{(290 / T)}$ & $2.0 \times 10^{-11}$ \\
\hline (R9) & $\mathrm{PPN} \rightarrow \mathrm{C}_{2} \mathrm{H}_{5} \mathrm{CO}_{3}+\mathrm{NO}_{2}$ & See Table 4 & $3.7 \times 10^{-4} \mathrm{~s}^{-1}$ \\
\hline (R10) & $\mathrm{C}_{2} \mathrm{H}_{5} \mathrm{CO}_{3}+\mathrm{NO}+\mathrm{O}_{2} \rightarrow \mathrm{C}_{2} \mathrm{H}_{5} \mathrm{O}_{2}+\mathrm{NO}_{2}+\mathrm{CO}_{2}$ & $6.7 \times 10^{-12} \times \mathrm{e}^{(340 / T)}$ & $2.1 \times 10^{-11}$ \\
\hline (R11) & $\mathrm{HO}+\mathrm{NO}+M \rightarrow \mathrm{HONO}+M$ & $7.4 \times 10^{-31} \times(T / 300)^{-2.4} \times[M]$ & $9.7 \times 10^{-12 b}$ \\
\hline (R12) & $\mathrm{HO}_{2}+\mathrm{NO}_{2}+M \rightarrow \mathrm{HO}_{2} \mathrm{NO}_{2}+M$ & (termolecular) & (termolecular) \\
\hline (R13) & $\mathrm{HO}_{2}+\mathrm{HO}_{2}+M \rightarrow \mathrm{H}_{2} \mathrm{O}_{2}+M$ & (termolecular) & (termolecular) \\
\hline (R14) & $\mathrm{CH}_{3} \mathrm{CO}_{3} \rightarrow 0.7 \mathrm{CH}_{3} \mathrm{CO}_{2}+0.3 \mathrm{CH}_{3} \mathrm{CO}_{2} \mathrm{H}$ & $5.0 \times 10^{-12} \times \sum \mathrm{RO}_{2}$ & $5.0 \times 10^{-12} \times \sum \mathrm{RO}_{2}$ \\
\hline (R15) & $\mathrm{C}_{2} \mathrm{H}_{5} \mathrm{CO}_{3} \rightarrow 0.7 \mathrm{C}_{2} \mathrm{H}_{5} \mathrm{CO}_{2}+0.3 \mathrm{C}_{2} \mathrm{H}_{5} \mathrm{CO}_{2} \mathrm{H}$ & $5.0 \times 10^{-12} \times \sum \mathrm{RO}_{2}$ & $5.0 \times 10^{-12} \times \sum \mathrm{RO}_{2}$ \\
\hline (R16) & $\mathrm{CH}_{3} \mathrm{O}_{2} \rightarrow 0.330 \mathrm{CH}_{3} \mathrm{O}+0.335 \mathrm{HCHO}+0.335 \mathrm{CH}_{3} \mathrm{OH}$ & $1.8 \times 10^{-13} \times \mathrm{e}^{(416 / T)} \times \sum \mathrm{RO}_{2}$ & $7.4 \times 10^{-13} \times \sum \mathrm{RO}_{2}$ \\
\hline (R17) & $\mathrm{C}_{2} \mathrm{H}_{5} \mathrm{O}_{2} \rightarrow 0.6 \mathrm{C}_{2} \mathrm{H}_{5} \mathrm{O}+0.2 \mathrm{CH}_{3} \mathrm{CHO}+0.2 \mathrm{C}_{2} \mathrm{H}_{5} \mathrm{OH}$ & $3.1 \times 10^{-13} \times \sum \mathrm{RO}_{2}$ & $3.1 \times 10^{-13} \times \sum \mathrm{RO}_{2}$ \\
\hline
\end{tabular}

${ }^{a}$ Rate constant expressions are from the Master Chemical Mechanism (MCM); Jenkin et al. (1997); Saunders et al. (2003) version 3.3.1, except Reactions (R7) and (R9), which are from Kabir et al. (2014).

${ }^{\mathrm{b}}$ Calculated using $\left[\mathrm{O}_{2}\right]=4.2 \times 10^{18}$ molecules $\mathrm{cm}^{-3}$

When used in polluted (i.e., high- $\mathrm{NO}_{x}$ ) environments, however, a drawback of the TD methods is that quantification of $\Sigma$ PN (and, to a lesser degree, also of $\Sigma$ PAN) is compromised because of the large error introduced from subtraction of the $\mathrm{NO}_{2}$ background, which is often 2-4 orders of magnitudes larger than the $\Sigma \mathrm{PN}$ abundance. In such high$\mathrm{NO}_{x}$ environments, however, mixing ratios of $\mathrm{RO}_{x}$ radicals are generally much smaller, $<100$ pptv (Wood et al., 2016), than those of $\mathrm{NO}_{2}$, such that a better strategy may be to quantify the peroxy and peroxyacyl radicals generated in stoichiometric amounts during TD of $\Sigma$ PN and/or $\Sigma$ PAN rather than $\mathrm{NO}_{2}$.

The $\mathrm{RO}_{x}$ radicals may be quantified by chemical ionization mass spectrometry (CIMS) (Hanke et al., 2002; Edwards et al., 2003; Chen et al., 2004; Slusher et al., 2004; Hornbrook et al., 2011); in fact, a TD-CIMS method has been developed to quantify PAN by titrating the peroxyacetyl radical with iodide reagent ion (Slusher et al., 2004). Other $\mathrm{RO}_{x}$ radical detection methods include LIF (Faloona et al., 2004; Heard, 2006; Fuchs et al., 2008; Dusanter et al., 2009) and peroxy radical chemical amplification (PERCA) coupled to $\mathrm{NO}_{2}$ detection (Cantrell et al., 1984; Hastie et al., 1991; Green et al., 2006; Liu and Zhang, 2014; Horstjann et al., 2014). The PERCA method is attractive as it allows the infrastructure of existing TD instruments with $\mathrm{NO}_{2}$ detection to be utilized.

In PERCA coupled to $\mathrm{NO}_{2}$ detection, concentrations of $\mathrm{RO}_{x}$ radicals are amplified by factors of between $\sim 20$ and $\sim 190$ through a series of catalytic reactions, usually involving parts-per-million by volume (ppmv, $10^{-6}$ ) mixing ratios of nitric oxide (NO) and percent levels of either carbon monoxide (CO) (Cantrell et al., 1984) or a short-chain hydrocarbon such as ethane $\left(\mathrm{C}_{2} \mathrm{H}_{6}\right)$ (Mihele and Hastie, 2000; Wood et al., 2016) (Reactions R1-R6, Table 3). Under these conditions, the peroxy radicals catalytically convert NO to $\mathrm{NO}_{2}$, and the amount of $\mathrm{NO}_{2}$ produced over a constant reaction period is proportional to the number of radicals that were present originally.

The measurement of peroxy radicals by PERCA is prone to matrix effects and interferences. For instance, a key operational parameter of any PERCA instrument is the radical chain length (CL) or amplification factor, which must be carefully calibrated. This chain length is suppressed by water vapor, whose presence increases the rates of radical loss on the inner walls of the PERCA chamber and the rates of certain gas-phase reactions, e.g., the reaction between the hydroperoxyl radical and water dimer $\left(\mathrm{HO}_{2} \cdot \mathrm{H}_{2} \mathrm{O}\right)$ with $\mathrm{NO}$ to peroxynitrous acid (HOONO), which isomerizes to nitric acid $\left(\mathrm{HONO}_{2}\right)($ Mihele and Hastie, 1998, 2000; Mihele et al., 1999).

The most obvious way to minimize wall reactions and to prevent weakly bound clusters such as $\mathrm{HO}_{2} \cdot \mathrm{H}_{2} \mathrm{O}$ from forming is to apply heat. When quantification of ambient $\mathrm{RO}_{x}$ radicals is the goal, this is avoided to prevent TD of $\Sigma$ PN or $\Sigma$ PAN (which are more abundant than free $\mathrm{RO}_{x}$ radicals). TD of $\Sigma$ PN or $\Sigma$ PAN produces radicals that in- 
terfere with the measurement of free $\mathrm{RO}_{x}$ radicals (Mihele and Hastie, 2000). In contrast, if measurement of $\Sigma P N$ or $\Sigma$ PAN is desired (such as in this paper), this interference is turned into a measurement principle. We are aware of only one prior attempt to quantify peroxy nitrates in this manner: Blanchard et al. (2013) thermally decomposed PAN eluting from a chromatographic column in the presence of $\mathrm{NO}$ and $\mathrm{CO}$ and quantified the amplified $\mathrm{NO}_{2}$ using luminol chemiluminescence.

In this paper, we probe the feasibility of selectively quantifying $\Sigma$ PN and $\Sigma$ PAN through their respective peroxy radical TD fragments by thermal decomposition peroxy radical chemical amplification cavity ring-down spectroscopy (TDPERCA-CRDS). The instrument uses a $405 \mathrm{~nm}$ blue diode laser CRDS (Paul and Osthoff, 2010) to monitor $\mathrm{NO}_{2}$ and the ethane-based chemical amplification scheme described by Wood et al. (2016), chosen because of ethane's lower toxicity compared to CO. Thermal dissociation profiles were determined for PAN, PPN, and PNA. Quantification of trace levels of PAN, PPN, and PNA by TD-PERCA-CRDS is demonstrated and compared to parallel measurements by iodide CIMS. The suitability of TD-PERCA-CRDS as a highly sensitive (sub-pptv) $\Sigma$ PN and $\Sigma$ PAN detection method for ambient measurements is discussed.

\section{Experimental section}

\subsection{TD-PERCA-CRDS}

\subsubsection{Single-channel inlet}

The majority of the experiments described in this paper were conducted using a single-channel TD-PERCA inlet that is described and depicted as Fig. S1 of the Supplement of Taha et al. (2018). Briefly, NO in $\mathrm{N}_{2}$ (100.2 ppmv, ScottMarrin, Riverside, CA) was scrubbed of $\mathrm{NO}_{2}$ by passing through iron(II) sulfate heptahydrate (99\%, Sigma-Aldrich, Oakville, ON) prior to being combined with either a flow of $\mathrm{N}_{2}$ gas (Praxair) or ethane (CP grade, 99\%, Matheson, Baskin Ridge, NJ). The gas mixture was directed towards the $80 \mathrm{~cm}$ long PERCA chamber $(1.27 \mathrm{~cm}$ or $1 / 2$ in. outer diameter - o.d.). When $\mathrm{NO}$ and $\mathrm{N}_{2}$ were mixed prior to the PERCA chamber, a "PERCA off" signal was observed, and ethane was added after the PERCA chamber to maintain constant flow (and pressure) through the system. Conversely, when NO and ethane were directed towards the PERCA chamber a "PERCA on" signal was observed. To maintain flows and pressures through the system during "PERCA on" mode, $\mathrm{N}_{2}$ was added to the inlet at an addition point after the PERCA chamber.

The inlet was connected to a four-channel CRDS described elsewhere (Odame-Ankrah, 2015). Briefly, concentrations of $\mathrm{NO}_{2}$ were monitored via its absorption at $405 \mathrm{~nm}$ (Paul and Osthoff, 2010). A flow containing ppmv levels of $\mathrm{O}_{3}$ in $\mathrm{O}_{2}$ was added to one CRDS channel to monitor $\mathrm{NO}_{x}$ (Fuchs et al., 2009). The remaining two channels were equipped with heated quartz tubes to monitor $\mathrm{NO}_{2}+\Sigma$ PAN and $\mathrm{NO}_{2}+\Sigma$ PAN + total alkyl nitrates $(\Sigma \mathrm{AN})$ (Paul et al., 2009). Each channel was connected to a MFC set to a flow rate of $\sim 0.84 \mathrm{slpm}$ All four CRDS cells were connected to sample the gases exiting the single-channel TD-PERCA inlet, though in principle a single CRDS detection channel would have sufficed to carry out the measurements.

When radical free "zero" air was sampled with the singlechannel inlet, a negative offset (up to 1 ppbv) was observed when the three-way solenoid valves were switched between PERCA "on" and "off" (data not shown). This artifact was not observed with the dual-channel setup (Sect. 2.1.2) and was not further investigated but may have been caused by differences in the ethane flows through the needle valve induced by pressure changes (up to 15 Torr) during switching between PERCA on and off.

\subsubsection{Dual-channel TD-PERCA-CRDS}

Time resolution, signal-to-noise ratio, and subtraction of background $\mathrm{NO}_{2}$ can be significantly improved in a PERCA instrument by implementing dual detection channels where both amplified and background signals are simultaneously monitored (Green et al., 2006; Cantrell et al., 1996). The dual-channel TD-PERCA setup used in this work is shown in Fig. 1. The NO reagent gas is added at the same flow rate and concentration as in the single-channel version near the tip of the inlet (after the zero air and calibration gas ports). The residence time prior to the ethane addition point $(\sim 2.0 \mathrm{~s})$ suffices to destroy $\mathrm{RO}_{x}$ radicals (via reaction with $\mathrm{NO}$ ) prior to chemical amplification. Addition of either $\mathrm{NO}$ or ethane is on-off modulated using two-way normally open valves connected to a pump via $50 \mu \mathrm{m}$ critical orifices (Lenox Laser, Glen Arm, MD) in a similar fashion as described earlier (Odame-Ankrah and Osthoff, 2011).

A portion of the sample flow of $\sim 0.74$ slpm was diverted prior to TD to monitor the "background" $\mathrm{NO}_{2}$ concentration in one CRDS channel. The remaining flow $(\sim 2.2 \mathrm{slpm})$ was passed through the heated quartz tube and PERCA chamber as described earlier and sampled by the other three CRDS channels to monitor background $\mathrm{NO}_{2}$ plus the amplified $\mathrm{NO}_{2}$ signal.

\subsubsection{Four-channel differential temperature TD-PERCA-CRDS}

An instrument with four identical measurement channels was set up to enable simultaneous quantification of $\mathrm{NO}_{2}$, $\mathrm{NO}_{2}+\Sigma \mathrm{PN}$, and $\mathrm{NO}_{2}+\Sigma \mathrm{PN}+\Sigma \mathrm{PAN}$. This version was similar to dual-channel setup described above and simply added two additional PERCA chambers; all three PERCA chambers were connected to separate CRDS channels. The quartz PERCA chamber was replaced with three identical 


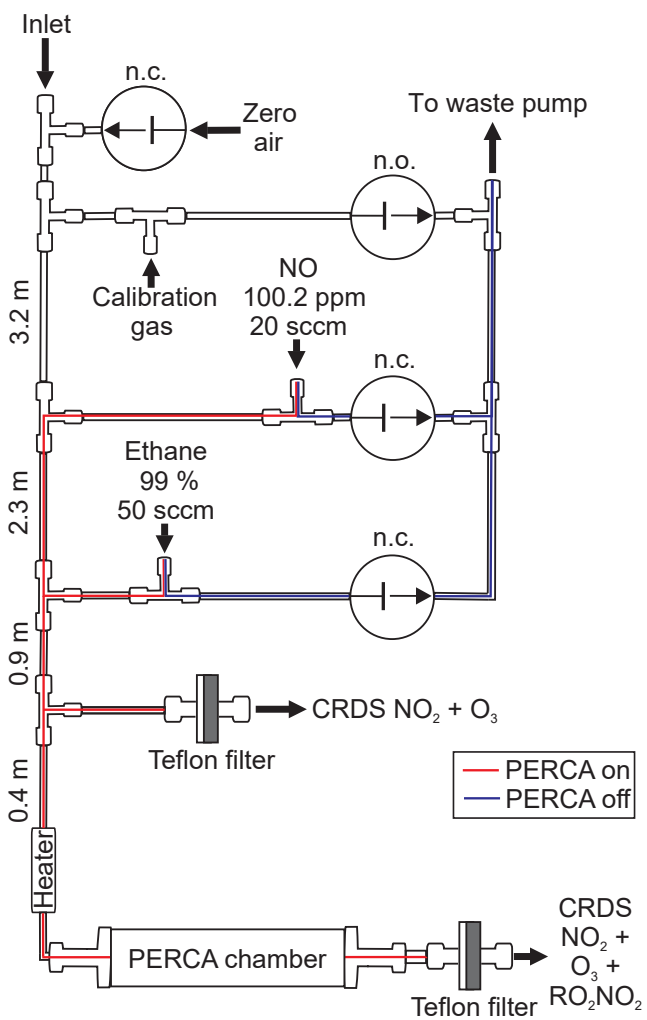

Figure 1. Schematic of the dual-channel thermal decomposition peroxy radical chemical amplification inlet. The inlet consists of a $60 \mathrm{~cm}$ long, $0.635 \mathrm{~cm}(1 / 4$ in.) o.d. quartz heater and an $80 \mathrm{~cm}$ long, $1.27 \mathrm{~cm}\left(1 / 2\right.$ in.) o.d. FEP Teflon ${ }^{\mathrm{TM}}$ reaction chamber. Reaction gases were added upstream of the PERCA chamber by closing the normally open valves connected to a waste pump via $50 \mu \mathrm{m}$ critical orifices. Background $\mathrm{NO}_{2}$ levels were monitored in a parallel detection channel by tapping into the inlet prior to thermal dissociation of peroxy nitrates.

$1.27 \mathrm{~cm}(1 / 2$ in.) o.d. and $0.95 \mathrm{~cm}(3 / 8 \mathrm{in}$.$) inner diameter$ (i.d.) fluorinated ethylene propylene (FEP) Teflon ${ }^{\mathrm{TM}}$ tubes externally heated using stretch-to-fit heaters (Watlow, St. Louis, MO) to 60,80 , and $100^{\circ} \mathrm{C}$, respectively. A common inlet filter was placed between the PERCA chambers and the ethane addition point. A flow restriction was placed ahead of the common filter to achieve a pressure of 380-400 Torr at a flow rate of 0.8 slpm per channel (total flow rate $\sim 3.2 \mathrm{slpm}$ ).

\subsection{Synthesis and delivery of PAN and PPN}

The synthesis of PAN and PPN from their corresponding anhydrides was described earlier (Mielke and Osthoff, 2012; Furgeson et al., 2011). Aliquots in tridecane were stored in $2.0 \mathrm{~mL}$ centrifuge tubes (VWR) in a freezer until needed.

To separate PAN and PPN from impurities generated during synthesis and storage (i.e., $\mathrm{NO}_{2}, \mathrm{HNO}_{3}$, and alkyl nitrates; Grosjean et al., 1994), a preparatory-scale gas chromatography (GC) setup (Fig. 2) was used. First, the contents

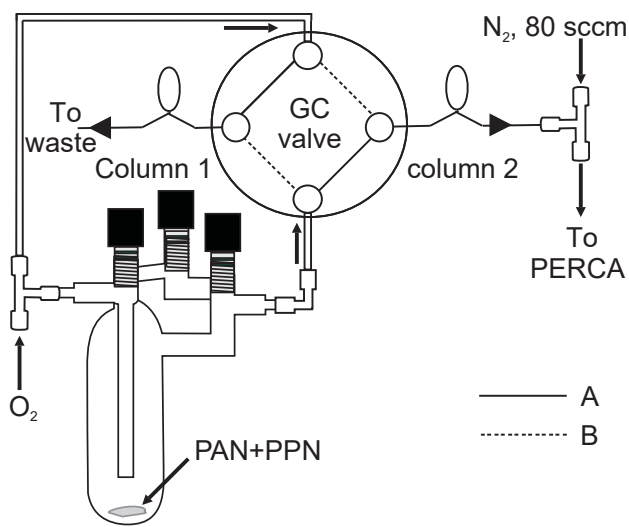

Figure 2. Setup for delivery of PAN and PPN using a gas chromatography column.

of two tubes containing PAN and PPN in tridecane were combined in a three-valve glass vessel. This vessel was connected to a two-position GC Valve (VICI Valco EH4C10WE, Houston, TX) and mildly pressurized ( $\sim 0.1 \mathrm{~atm}$ above ambient) using oxygen (Praxair) delivered through a $10 \mu \mathrm{m}$ critical orifice. Two megabore capillary GC columns (Restek RTX1701, $0.53 \mathrm{~mm}$ i.d., $1.00 \mu \mathrm{m}$ film thickness, State College, PA) of equal lengths $(3 \mathrm{~m})$ were connected to the ports adjacent to the one connected to the glass vessel. The outlet of one GC column was connected to the PERCA inlet, whereas the other was exhausted into a waste line. The port opposite to the glass vessel was also pressurized with oxygen such that both columns remained under flow at all times. Gases were delivered by switching the valve to position A (Fig. 2) for $\sim 40 \mathrm{~s}$. The output of the preparatory-scale GC was diluted with zero air or air passed through a custom-built scrubber system to meet the sample flow requirements of the TDPERCA CRDS and/or CIMS. The relative humidity (RH) of the gases delivered was monitored using a temperature- $\mathrm{RH}$ probe (VWR) placed inline.

The preparatory-scale GC setup allowed delivery of short "bursts" of PAN and PPN. To deliver a constant and low PAN concentration over prolonged time periods, air was drawn from a $4000 \mathrm{~L}$ Teflon chamber, initially filled with scrubbed (i.e., PAN-free) air and to which the head space above a PAN/tridecane solution had been added. An internal mixing fan ensured constant output.

\subsection{Synthesis and delivery of PNA}

\subsubsection{Batch sample}

A batch PNA sample was synthesized from reaction of nitronium tetrafluoroborate $\left(\mathrm{NO}_{2} \mathrm{BF}_{4} ;\right.$ Sigma-Aldrich) with $\mathrm{H}_{2} \mathrm{O}_{2}$ as described by D. X. Chen et al. (2017). Briefly, a $50 \% \mathrm{H}_{2} \mathrm{O}_{2}$ solution (Sigma-Aldrich) was concentrated using a gentle $\mathrm{N}_{2}$ flow over a period of several days. A small 
aliquot $(200 \mu \mathrm{L})$ of concentrated $\mathrm{H}_{2} \mathrm{O}_{2}$ was placed in a threevalve glass vessel cooled to $0^{\circ} \mathrm{C}$ using an external circulating chiller, and $120 \mathrm{mg}$ of $\mathrm{NO}_{2} \mathrm{BF}_{4}$ were added. The headspace of the glass vessel was flushed with a $50 \mathrm{sccm}$ flow of $\mathrm{N}_{2}$ delivered by a MFC. This flow delivered very high concentrations and contained substantial and variable amounts of impurities (mainly $\mathrm{HNO}_{3}$ ), even when the vessel temperature was lowered to $-20^{\circ} \mathrm{C}$. The batch sample was used to calibrate the CIMS against TD-CRDS (Sect. 2.4).

\subsubsection{Photolysis source}

Gas flows containing low and reproducible concentrations of PNA were generated dynamically in a similar fashion to the method described by Veres et al. (2015) by combining the output of a $\mathrm{HO}_{2}$ photochemical source with $\mathrm{NO}_{2}$. Ultrapure $\mathrm{N}_{2}$ (Praxair) was passed through a bubbler filled with deionized water at a flow rate of $100 \mathrm{sccm}$ and combined with $2 \mathrm{sccm}$ of $\mathrm{O}_{2}$ (Praxair). This mixture was passed through a $1 / 4$ in. $(0.635 \mathrm{~cm})$ o.d. quartz tube partially illuminated by a low-pressure $185 \mathrm{~nm}$ mercury quartz lamp (Jelight 95-21002 , Irvine, CA). This generated a mixture of $\mathrm{O}_{3}(\sim 30 \mathrm{ppbv}$ after dilution), $\mathrm{OH}$ and $\mathrm{HO}_{2}$, whose concentrations were controlled with a sliding metal sleeve (VWR) which modified the length of the quartz tubing that was illuminated. This flow was combined with between 4 and $16 \mathrm{ppmv} \mathrm{NO}_{2}$ to yield a gas mixture containing PNA which was immediately $(<5 \mathrm{~cm}$ tube length) diluted with zero or scrubbed air flowing at a rate slightly greater than the amount sampled by the instruments. The $\mathrm{NO}_{2}$ gas stream was generated by mixing between 1.4 and $3.0 \mathrm{sccm}$ of $\mathrm{NO}$ (100.2 ppmv in $\mathrm{N}_{2}$; Scott-Marrin, Riverside, CA) with a slightly less than stoichiometric amount of $\mathrm{O}_{3}$ in $\sim 20 \mathrm{sccm} \mathrm{O}_{2}$, generated by illuminating $\mathrm{O}_{2}$ with a low-pressure $254 \mathrm{~nm}$ mercury quartz lamp (Jelight). The amount of PNA delivered from this source was quantified by TD-CRDS.

\subsection{Chemical ionization mass spectrometry}

The CIMS and its operation have been described elsewhere (Mielke et al., 2011; Mielke and Osthoff, 2012; Abida et al., 2011). For measurements of PAN or PPN, the instrument was operated with iodide reagent in declustering mode (collisional dissociation chamber voltage of $-24.7 \mathrm{~V}$ ) and sampled through a short section of $1.27 \mathrm{~cm}(1 / 2$ in.) o.d. PFA Teflon ${ }^{\mathrm{TM}}$ tubing heated to $190^{\circ} \mathrm{C}$. The inlet flow was diluted with nitrogen saturated with water vapor to maintain a minimum RH of $\sim 16 \%$ with the ion-molecule reaction region (IMR). PAN and PPN were quantified using the acetate and propionate ions $(\mathrm{m} / z 59$ and 73$)$. Ion counts were normalized to $10^{6}$ reagent ion counts prior to presentation. The instrument response factor for PAN was calibrated against TD-CRDS (Mielke and Osthoff, 2012) and was $11 \pm 3 \mathrm{~Hz} \mathrm{pptv}^{-1}$.

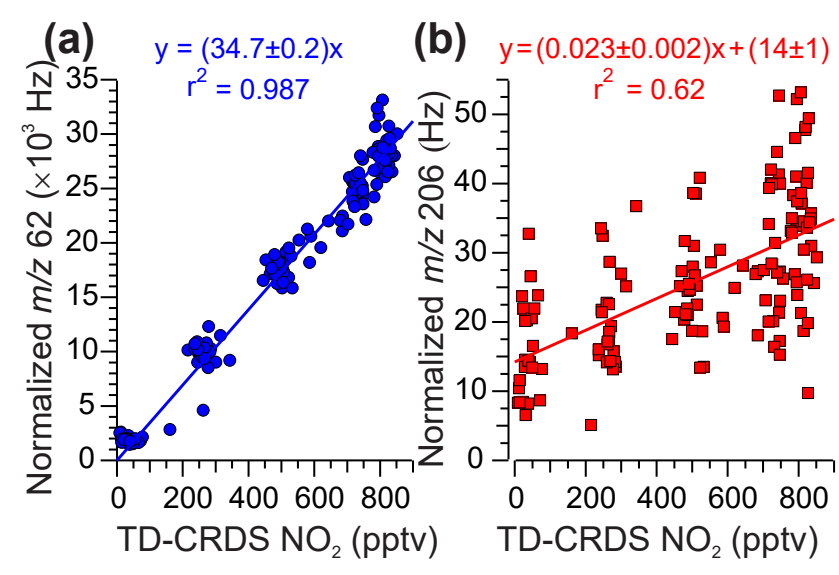

Figure 3. Calibration of CIMS response factors against TD-CRDS operated with its inlet heated to $120^{\circ} \mathrm{C}$ and without amplification. (a) $m / z$ 62. (b) $m / z$ 206. CIMS counts were normalized to $10^{6} \mathrm{I}^{-}$ counts.

For PNA measurements, the CIMS was operated with an ambient temperature inlet and in clustering mode (collisional dissociation chamber voltage $=-8.9 \mathrm{~V}$ ); under these conditions, $\sim 5 \times 10^{5} \mathrm{I}^{-}$and $\sim 2 \times 10^{4} \mathrm{I}^{-} \cdot \mathrm{H}_{2} \mathrm{O}$ ions were observed. Mixing ratios of PNA were monitored primarily using $\mathrm{NO}_{3}^{-}$at $m / z 62$, which is formed via PNA decomposition within the IMR (Abida et al., 2011). The $\mathrm{HNO}_{3} \cdot \mathrm{I}^{-}$and $\mathrm{HO}_{2} \mathrm{NO}_{2} \cdot \mathrm{I}^{-}$clusters at $m / z 190$ and $m / z 206$ (Veres et al., 2015; D. X. Chen et al., 2017) were also monitored.

The PNA response factors were determined using TDCRDS (i.e., without added PERCA gases) with its inlet operated at $120^{\circ} \mathrm{C}$ (Fig. 3). Assuming that one equivalent of $\mathrm{NO}_{2}$ is generated for each PNA molecule thermally dissociated, the CIMS response factors, normalized to $10^{6} \mathrm{I}^{-}$counts, were $34.7 \pm 0.2 \mathrm{~Hz} \mathrm{pptv}^{-1}$ and $0.023 \pm 0.002 \mathrm{~Hz} \mathrm{pptv}^{-1}$ at $\mathrm{m} / \mathrm{z} 62$ and 206, respectively. These response factors are consistent with calibration factors by other groups (Veres et al., 2015; D. X. Chen et al., 2017), with the low response at $m / z, 206$ rationalized by the low number of $\mathrm{I}^{-} \cdot \mathrm{H}_{2} \mathrm{O}$ ions. Even though the CIMS response at $m / z 62$ is not specific (Abida et al., 2011), it was used in the laboratory experiments presented here to monitor PNA rather than $m / z 206$ because of its larger response factor and thus higher sensitivity.

\subsection{Box model simulations}

Box model simulations were carried out using a subset of the Master Chemical Mechanism (MCM) V3.3.1 obtained from http://mcm.leeds.ac.uk/MCM (Jenkin et al., 1997, 2012; Saunders et al., 2003) and the Kinetic Preprocessor (KPP) (Sandu and Sander, 2006) to aid in the interpretation of observations. Details are given in the Supplement. 
Table 4. Arrhenius parameters for thermal dissociation of selected PN, PAN, PPN, PAA, and $\mathrm{O}_{3}$.

\begin{tabular}{|c|c|c|c|c|c|}
\hline Molecule & $A\left(s^{-1}\right)$ & $E_{\mathrm{a}}\left(\mathrm{kJ} \mathrm{mol}^{-1}\right)$ & Reference & $\begin{array}{l}T \text { needed to } \\
\text { dissociate } \\
0.1 \%\left({ }^{\circ} \mathrm{C}\right)^{\mathrm{b}}\end{array}$ & $\begin{array}{r}T \text { needed } \\
\text { to dissociate } \\
99.9 \%\left({ }^{\circ} \mathrm{C}\right)^{\mathrm{a}}\end{array}$ \\
\hline $\mathrm{HO}_{2} \mathrm{NO}_{2}$ (PNA) & $7.3 \times 10^{14 b}$ & $88.1 \pm 4.4$ & Atkinson et al. (1997) & 24 & 123 \\
\hline $\mathrm{CH}_{3} \mathrm{O}_{2} \mathrm{NO}_{2}(\mathrm{MPN})$ & $1.1 \times 10^{16}$ & $88.1 \pm 4.4$ & Atkinson et al. (1997) & 3 & 86 \\
\hline $\mathrm{C}_{2} \mathrm{H}_{5} \mathrm{O}_{2} \mathrm{NO}_{2}(\mathrm{EPN})$ & $8.8 \times 10^{15}$ & $86.5 \pm 8.7$ & Atkinson et al. (1997) & 0 & 82 \\
\hline $\mathrm{CH}_{3} \mathrm{C}(\mathrm{O}) \mathrm{O}_{2} \mathrm{NO}_{2}(\mathrm{PAN})$ & $2.8 \times 10^{16}$ & $113 \pm 2$ & Kabir et al. (2014) & 73 & 174 \\
\hline $\mathrm{C}_{2} \mathrm{H}_{5} \mathrm{C}(\mathrm{O}) \mathrm{O}_{2} \mathrm{NO}_{2}(\mathrm{PPN})$ & $2.36 \times 10^{16}$ & $113 \pm 2$ & Kabir et al. (2014) & 75 & 176 \\
\hline $\mathrm{CH}_{3} \mathrm{C}(\mathrm{O}) \mathrm{O}_{2} \mathrm{H}(\mathrm{PAA})$ & $10^{14}$ & $134 \pm 8$ & Schmidt and Sehon (1963) & 206 & 377 \\
\hline $\mathrm{CH}_{3} \mathrm{C}(\mathrm{O}) \mathrm{O}_{2} \mathrm{H}(\mathrm{PAA})$ & $1.15 \times 10^{13}$ & 136 & Devush et al. (1983) & 247 & 450 \\
\hline $\mathrm{CH}_{3} \mathrm{C}(\mathrm{O}) \mathrm{O}_{2} \mathrm{H}(\mathrm{PAA})$ & $5 \times 10^{14}$ & $168 \pm 4$ & Sahetchian et al. (1992) & 300 & 492 \\
\hline $\mathrm{O}_{3}$ & $1.3 \times 10^{10 a}$ & 92.8 & $\begin{array}{l}\text { Jones and Davidson (1962); } \\
\text { Heimerl and Coffee (1979) }\end{array}$ & 180 & 433 \\
\hline
\end{tabular}

${ }^{\text {a }}$ Calculated assuming a pressure of 550 Torr and temperature of $298 \mathrm{~K}$.

${ }^{b}$ Assuming a contact time of $4 \mathrm{~ms}$ at the maximum temperature (Paul et al., 2009).

\section{Results}

\subsection{Thermal dissociation profiles}

The TD profiles of PNA, PAN, and PPN were measured by TD-CRDS (i.e., without amplification) with the singlechannel inlet and are shown in Fig. 4. The superimposed trend lines are simulations based on the TD model introduced by Paul et al. (2009) and the Arrhenius parameters in Table 4 and are consistent with the observations. The TD profiles of PNA and PAN / PPN partially overlap and are consistent with the 5\% / $95 \%$ ranges given in Fig. 3 of Wooldridge et al. (2010). PNA and PAN or PPN fully dissociated at temperatures of 120 and $250^{\circ} \mathrm{C}$, respectively. These temperatures were used in subsequent experiments when complete dissociation of either PNA or PAN and PPN was desired. Also shown in Fig. 4 is the TD-PERCA-CRDS signal observed when sampling $\mathrm{O}_{3}$, an interfering species (see Sect. 3.6.1).

\subsection{Measurement of PAN and PPN by TD-PERCA-CRDS}

A time series demonstrating amplification of PAN and PPN in the TD-PERCA-CRDS is shown in Fig. 5. In this experiment, PAN and PPN were delivered via the preparatory-scale GC (Fig. 2), and the single-channel setup (Sect. 2.1.1) was used.

PAN and PPN eluted from the GC column after 3 and $6 \mathrm{~min}$, respectively. The compounds eluted as plateaus because of the relatively long $(\sim 30 \mathrm{~s})$ injection time. In Fig. 5a, PAN and PPN are observed only by the heated $\left(\mathrm{NO}_{2}+\Sigma\right.$ PAN) TD-CRDS channel. This channel was operated with its quartz inlet at $250^{\circ} \mathrm{C}$ to quantitatively (see Fig. 5 of Paul et al., 2009) decompose PAN and PPN to $\mathrm{NO}_{2}$. In this example, mixing ratios of $2.00 \pm 0.09 \mathrm{ppbv}$ and $1.86 \pm 0.12 \mathrm{ppbv}$ were observed, respectively (errors

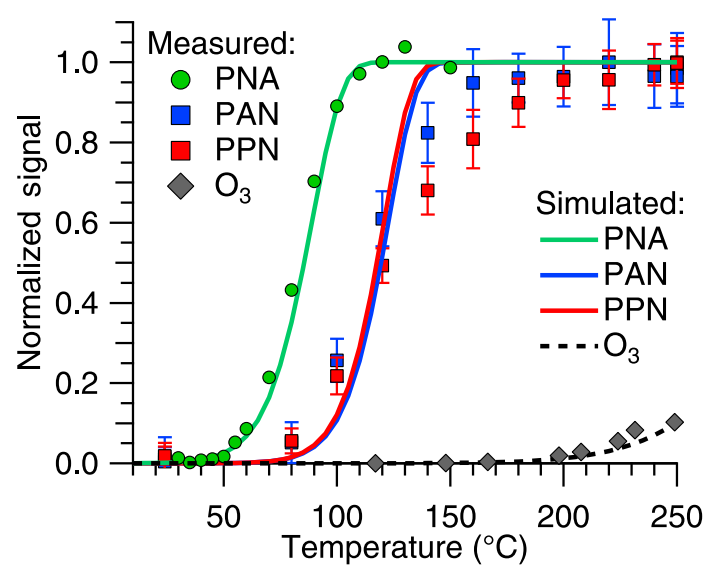

Figure 4. Normalized thermal dissociation profiles of PNA, PAN, $\mathrm{PPN}$, and $\mathrm{O}_{3}$ as a function of inlet set temperature. Superimposed trend lines are simulations based on the TD model introduced by Paul et al. (2009). The PNA, PAN, and PPN data were observed by TD-CRDS without amplification gases present, whereas the $\mathrm{O}_{3}$ data were observed by TD-PERCA-CRDS. The error bars represent standard deviations of $1 \mathrm{~s}$ data.

are $1 \sigma$ of $1 \mathrm{~s}$ data). After the PERCA heater was set to $250^{\circ} \mathrm{C}$ as well, similar amounts of $\mathrm{NO}_{2}, 2.04 \pm 0.09 \mathrm{ppbv}$ and $1.97 \pm 0.12 \mathrm{ppbv}$ were observed in the ambient temperature channel for PAN and PPN, respectively. Marginally higher amounts were observed in the heated CRDS channel $(2.42 \pm 0.10$ and $2.06 \pm 0.14$ ppbv) (Fig. 5b). The lower amounts observed in the unheated CRDS channel result from recombination of peroxyacyl radicals with $\mathrm{NO}_{2}$ (mostly in the unheated PERCA chamber), which suppresses the signal in the unheated CRDS channel but not in the heated one. Hence, the $\mathrm{NO}_{2}+\Sigma$ PAN data are a more accurate measure of the PAN and PPN concentrations delivered. 


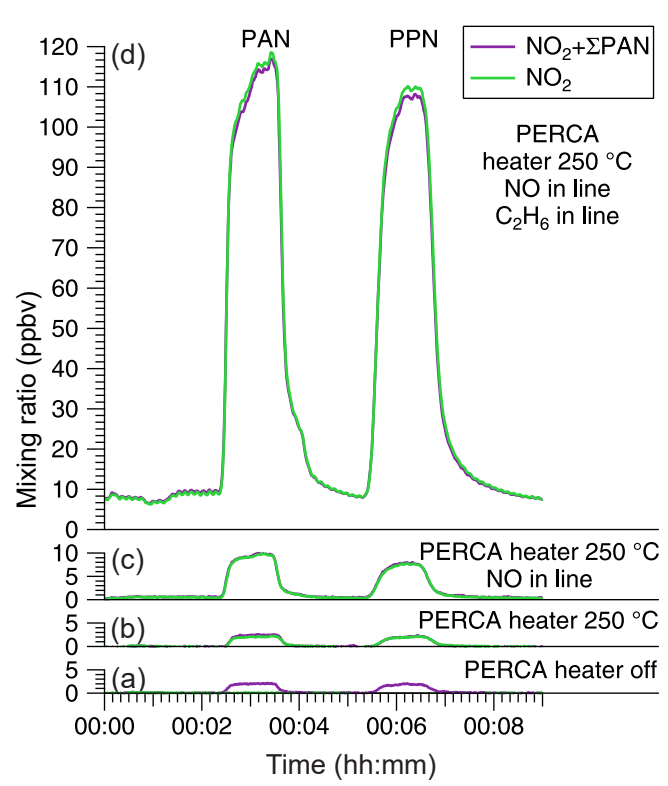

Figure 5. Peroxy radical chemical amplification of peroxyacetic and peroxypropionic nitric anhydride (PAN and PPN) delivered via a megabore GC column. (a) Time series of the signal observed by cavity ring-down spectroscopy in the ambient temperature $\left(\mathrm{NO}_{2}\right.$; green $)$ and heated $\left(\mathrm{NO}_{2}+\Sigma \mathrm{PAN}\right.$; purple) channels with the PERCA heater off. (b) Same as (a) with the PERCA heater switched on. (c) Same as (b) with 0.75 ppmv NO added. (d) Same as (c) with $1.5 \% \mathrm{C}_{2} \mathrm{H}_{6}$ added. The amplification factor is determined from the ratio of the ambient temperature (i.e., $\mathrm{NO}_{2}$ ) CRDS signal observed in (d) divided by that observed in (b).

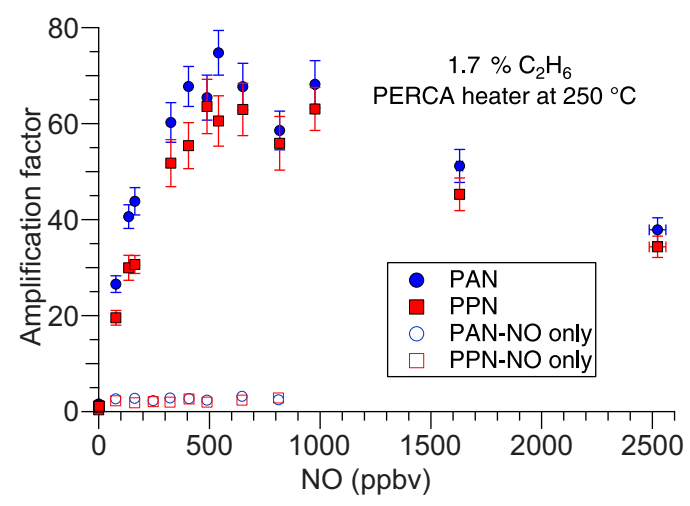

Figure 6. TD-PERCA-CRDS amplification factors of $\sim 0.5 \mathrm{ppbv}$ PAN and $\sim 1.3$ ppbv PPN as a function of NO mixing ratio at $\mathrm{RH}=0 \%$. The error bars represent standard deviations of $1 \mathrm{~s}$ data.

Because PAN and PPN dissociate with 1:1 stoichiometry, the amount of peroxyacyl radicals produced during thermal dissociation is the same as the amount of $\mathrm{NO}_{2}$ generated. When $\sim 0.75$ ppmv of NO was added (Fig. $5 \mathrm{c}$ ), the peroxyacyl and, subsequently, the methyl (or ethyl) peroxy and the hydroperoxyl radicals oxidize $\mathrm{NO}$ to $\mathrm{NO}_{2}$ (Reactions R8/R10, R1/R5, and R3; Table 3) and the $\mathrm{NO}_{2}$ signal relative to the signal obtained in the absence of $\mathrm{NO}$ is amplified by a factor of 4 . The ratios observed (Fig. 5c relative to Fig. 5 b) were $4.0 \pm 0.2$ and $3.8 \pm 0.3$ for PAN and PPN, respectively, and are consistent with earlier observations at lower NO mixing ratios (i.e., Fig. 6 of Paul and Osthoff, 2010).

Next, NO and ethane were added at mixing ratios $\left(0.75 \mathrm{ppmv} \mathrm{NO}\right.$ and $\left.1.5 \% \quad \mathrm{C}_{2} \mathrm{H}_{6}\right)$ that Wood et al. (2016) determined to be optimal for ambient temperature PERCA. Under these conditions, the signals amplified to $116.0 \pm 1.3 \mathrm{ppbv}$ and $109.3 \pm 0.7 \mathrm{ppbv}$ (Fig. 5d), corresponding to CLs (relative to Fig. 4b) of $48 \pm 2$ and $53 \pm 4$ for PAN and PPN, respectively.

In the presence of ethane, marginally lower $\mathrm{NO}_{2}$ concentrations (98.7 and $98.1 \%$ ) were observed in the heated, $\mathrm{NO}_{2}$ $+\Sigma$ PAN TD-CRDS channel (compared to the absence of ethane). Partial scrubbing of $\mathrm{NO}_{2}$ in heated quartz cells has been anecdotally observed in our group's and also others' (Womack et al., 2017) TD instruments; this effect varies between quartz cells and with sample history. Since the effect was relatively minor, it was neglected in this work.

\subsection{Optimization of TD-PERCA amplification factors}

Sequences, such as the one shown in Fig. 5, were used to determine conditions leading to optimum amplification factors. The largest amplification factors were obtained with an ethane mixing ratio of $\sim 1.6-1.7 \%$ (data not shown).

Figure 6 shows how the chain length varies with NO mixing ratio. In the absence of ethane, amplification factors of $\sim 4$ were observed (Fig. 6, open symbols), consistent with the results shown in Fig. 5c. When $1.7 \%$ ethane was added, the amplification factor increased with $\mathrm{NO}$ mixing ratio up to a maximum at $550 \pm 150 \mathrm{ppbv}$ and then decreased, qualitatively consistent with the results reported by Wood et al. (2016).

The amplification factors shown in Fig. 6 were slightly larger for PAN than for PPN mainly because the PPN mixing ratio of $\sim 1.3 \mathrm{ppbv}$ exceeded the optimum concentration range for PERCA (see Sect. 3.5.2).

\subsection{Parallel measurement of PNA by TD-PERCA-CRDS and CIMS}

A sample time series showing TD-PERCA-CRDS measurements of photochemically generated PNA in scrubbed air is presented in Fig. 7. Here, the TD-PERCA-CRDS was operated with the dual-channel inlet (Fig. 1) at $120^{\circ} \mathrm{C}$ and with $1.6 \% \mathrm{C}_{2} \mathrm{H}_{6}$ and $316 \pm 3$ ppbv of $\mathrm{NO}$ (suboptimal NO mixing ratios). Figure $7 \mathrm{a}$ shows the $\mathrm{NO}_{2}$ mixing ratios in the reference $\mathrm{NO}_{2}$ channel (green trace) and in the TD-PERCACRDS channel (grey trace). In this example, the mixing ratio of PNA was changed approximately every $2 \mathrm{~min}$ by moving a sliding cover within the photochemical source. 


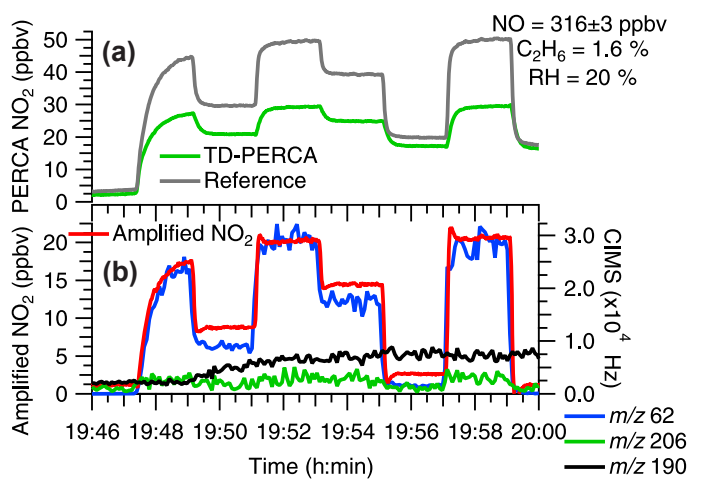

Figure 7. (a) Sample time series of PNA observed by TD-PERCACRDS in the reference, $\mathrm{NO}_{2}$ channel (shown in green), and PERCA channel (grey). (b) (left) Difference signal between amplified and reference channel (shown in red). (right) CIMS counts (normalized to $\left.10^{6} \mathrm{I}^{-}\right)$at $m / z 62$, the major fragment $\left(\mathrm{NO}_{3}^{-}\right)$expected from PNA; at $m / z 206$ (multiplied by a factor of 100 for clarity), the $\mathrm{HNO}_{4} \cdot \mathrm{I}^{-}$cluster; and at $m / z 190$, the $\mathrm{HNO}_{3} \cdot \mathrm{I}^{-}$cluster.

The difference between these two signals is displayed in Fig. 7b (red trace, left-hand axis). Superimposed in Fig. 7b (right-hand axis) are the CIMS responses at $m / z 62\left(\mathrm{NO}_{3}^{-}\right)$, $m / z, 206\left(\mathrm{HNO}_{4} \cdot \mathrm{I}^{-}\right.$, multiplied by a factor of 100 for clarity), and $m / z 190\left(\mathrm{HNO}_{3} \cdot \mathrm{I}^{-}\right)$.

The photochemical source co-generates $\mathrm{OH}$ which is lost on the inner walls of the quartz tubing or is titrated by $\mathrm{NO}_{2}$ or $\mathrm{NO}$ to $\mathrm{HNO}_{3}$ or $\mathrm{HONO}$, respectively. Conceivably, the co-generation of $\mathrm{HNO}_{3}$ could interfere with quantification of PNA by CIMS at $m / z$ 62. However, when the photolysis source was turned off at $\sim 19: 59$ (Fig. 7), $\mathrm{HNO}_{3}$ was still observed for some time after at $\mathrm{m} / \mathrm{z} 190$ due to slow desorption from the inner walls of the connecting tubing, whereas the ion counts at $m / z 62$ quickly $(<10 \mathrm{~s})$ returned to background values close to $0 \mathrm{~Hz}$, indicating that the contribution of $\mathrm{HNO}_{3}$ to ion counts at $m / z 62$ was negligible.

The scatter plot of the TD-PERCA-CRDS and CIMS data at $m / z$ 62, multiplied by the CIMS response factor determined in Fig. 3a, is shown in Fig. 8a as dark blue circles. The signals by the two instruments are highly correlated $\left(r^{2}=0.979\right)$, consistent with both instruments measuring the same molecule, PNA. The slope of this plot $(26.3 \pm 0.4)$ equals the TD-PERCA-CRDS amplification factor for PNA. In contrast, the scatter plot of TD-PERCA-CRDS with the CIMS response at $m / z 206$ was unusable because of the latter's poor signal-to-noise ratio (Fig. 3b).

\subsection{Factors affecting amplification factors}

The amplification factor for PNA shown in Fig. 8a is less than observed for PAN in Fig. 8b and for PAN and PPN under optimal conditions (Fig. 6). Though in this particular example the lower amplification factor was due to the less than op-
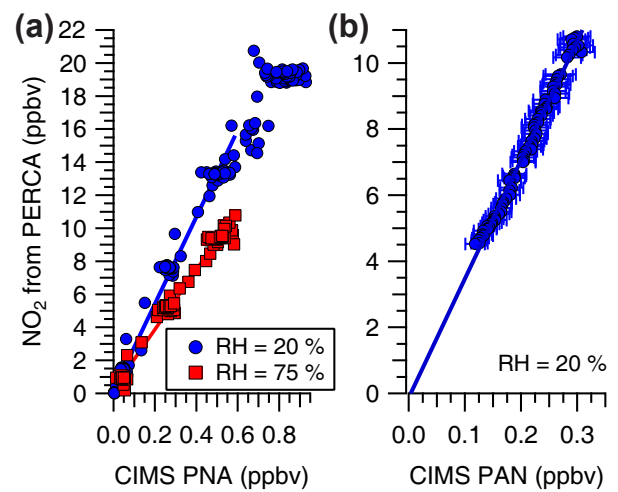

Figure 8. Scatter plots of TD-PERCA-CRDS and CIMS measurements. (a) Sample PNA calibrations at an NO mixing ratio of $316 \pm 3 \mathrm{ppbv}$ and TD-PERCA inlet temperature of $120^{\circ} \mathrm{C}$. For mixing ratios $<0.6 \mathrm{ppbv}$, the intercept and slope of the linear fits are $(0.2 \pm 0.1) \mathrm{ppbv}$ and $26.3 \pm 0.4\left(r^{2}=0.979\right)$ at $\mathrm{RH}=20 \%$ and $(0.3 \pm 0.1) \mathrm{ppbv}$ and $18.0 \pm 0.2\left(r^{2}=0.985\right)$ at $\mathrm{RH}=75 \%$. (b) Sample PAN calibration at a NO mixing ratio of $662 \pm 2 \mathrm{ppbv}$ and TD-PERCA inlet temperature of $250^{\circ} \mathrm{C}$ and $\mathrm{RH}=20 \%$. The intercept and slope of the linear fit is $(-0.13 \pm 0.09) \mathrm{ppbv}$ and $36.0 \pm 0.4\left(r^{2}=0.990\right)$.

timal amount of NO added, lower amplification factors for PNA than for PAN were generally observed, even when optimum NO mixing ratios were used.

The obvious difference is that different radicals, $\mathrm{HO}_{2}$ in the case of PNA and a peroxyacyl radical $\left(\mathrm{RC}(\mathrm{O}) \mathrm{O}_{2}\right)$ in the case of PAN or PPN, are generated initially. However, in both cases, the $\mathrm{HO}_{2}$ / $\mathrm{HO}$ radical pair is the main carrier of the amplification, such that this initial difference should only have a marginal effect. Wood et al. (2016) estimated the uncertainty arising from the range in peroxy radical reactivity to $\pm 9 \%$.

Experimental parameters that can affect the amplification factor include relative humidity, radical concentration, and the PERCA inlet temperature; these factors are probed separately in the following sections. In each case, box model simulations were carried out (see the Supplement) to aid in the interpretation of the data.

\subsubsection{Dependence of chain lengths on relative humidity}

We repeated the experiment described in Sect. 3.4 with the scrubbed air humidified to $75 \%$ RH by passing the make-up air through a bubbler. The resulting scatter plot is superimposed in Fig. 8a as red squares. Indeed, the amplification factor for PNA was lowered from $26.3 \pm 0.4$ to $18.0 \pm 0.2$ when the RH was increased from 20 to $75 \%$. Following these observations, the RH dependence was investigated systematically at constant NO and ethane concentrations. The results are summarized in Fig. 9.

The amplification factor decreased by $(2.0 \pm 0.6) \%$ for every $10 \%$ increase in RH. This RH dependence is less than reported for ambient temperature PERCA: between a RH of 


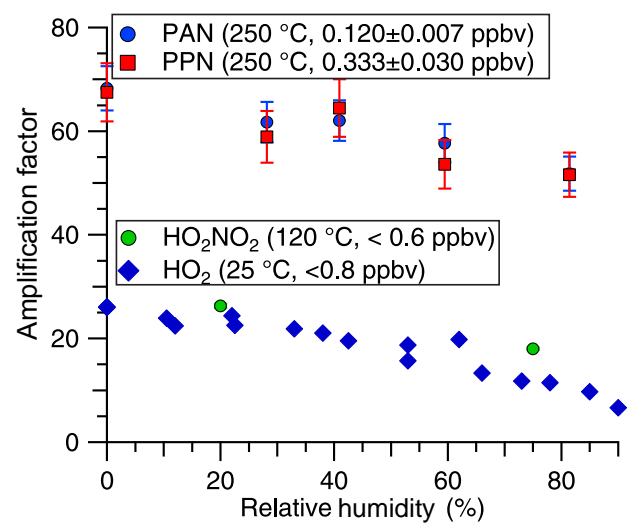

Figure 9. TD-PERCA-CRDS amplification factor as a function of relative humidity at an ethane mixing ratio of $1.6 \%$ and with $\mathrm{NO}$ mixing ratios of $644 \pm 2$ and $316 \pm 3$ ppbv for the PAN / PPN experiments and the PNA experiments, respectively. The PAN and PPN mixing ratios were $0.120 \pm 0.007$ and $0.333 \pm 0.030 \mathrm{ppbv}$, respectively. The PNA mixing ratio was varied between 0 and $0.6 \mathrm{ppbv}$. The room temperature $\mathrm{HO}_{2}$ data are from Wood et al. (2016).

0 and $50 \%$, for example, the response of room temperature PERCA dropped by $30 \%$ (Wood et al., 2016), whereas that of TD-PERCA decreased by $15 \%$. A reduced RH dependence is expected as the elevated temperature suppresses formation of $\mathrm{HO}_{2} \cdot \mathrm{H}_{2} \mathrm{O}$ (Kanno et al., 2006), whose reaction with NO is a major radical sink (Mihele and Hastie, 1998, 2000; Mihele et al., 1999). This interpretation is supported by box model simulations, which show a reduced RH dependence of the CL at higher temperatures (Fig. S4 in the Supplement). In addition, we speculate that reactions of radicals on the inner walls of PERCA tubing are reduced at higher inlet temperature.

\subsubsection{Dependence of chain lengths on radical concentration: dynamic range}

It is well known in the PERCA community that the chain lengths decrease at high radical concentrations due to radical-radical reactions. Figure $8 \mathrm{a}$ and $\mathrm{b}$ demonstrate that the response of TD-PERCA-CRDS is linear for both PNA and PAN / PPN at low, atmospherically relevant mixing ratios (i.e., below $\sim 600 \mathrm{pptv}$ ). The linear dynamic range is similar for PNA and PAN and PPN since the radical chain carriers are the same for both.

Figure 10 summarizes the PERCA responses as functions at larger PAN / PPN mixing ratios. The largest amplification factor, $69 \pm 5$, was observed when the TD-PERCA inlet was operated at $250^{\circ} \mathrm{C}$ with PAN or PPN mixing ratios $\leq 600$ pptv. Shorter chain lengths were observed at higher mixing ratios (e.g., $62 \pm 2$ at $1300 \mathrm{pptv}, 53 \pm 4$ at $2100 \mathrm{pptv}$, and $48 \pm 2$ at 2400 pptv, respectively). Thus, the amplification factor is concentration-dependent at $\mathrm{RO}_{2}$ mixing ratios

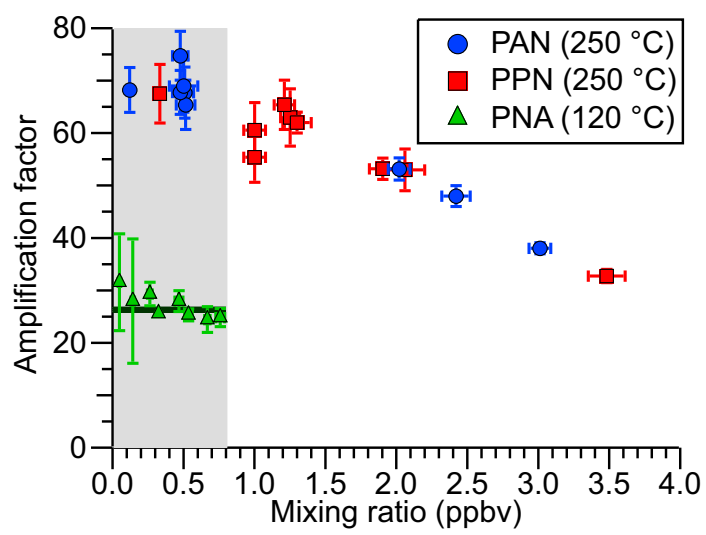

Figure 10. TD-PERCA-CRDS amplification factors as a function of PAN, PPN, and PNA mixing ratio. Errors bars correspond to $\pm 1 \sigma$ standard deviation. Mixing ratios of $\mathrm{NO}$ and ethane were $500 \pm 50 \mathrm{ppbv}$ and $\sim 1.6 \%$, respectively. The grey underlay indicates the linear range. The dark green line corresponds to $26.3 \pm 0.4$ (slope of data shown in Fig. 8a).

above 600 pptv and is constant under atmospherically relevant trace conditions.

PERCA reactors utilizing $\mathrm{CO}$ as a chain carrier show nonlinearity at $\mathrm{RO}_{2}$ mixing ratios above $\sim 200 \mathrm{pptv}$ (Hastie et al., 1991), while room temperature ethane-based PERCA has a reported linear dynamic range up to $\sim 800 \mathrm{pptv}$ (Wood et al., 2016). The greater dynamic range with ethane arises because of lower chain lengths and radical concentrations in the reactor and hence reduced radical-radical termination reactions (Wood et al., 2016). The linear range of the ethane TD-PERCA reactor of $\sim 600 \mathrm{pptv}$ falls in between these two extremes, as the CL and radical concentrations are greater than ethane PERCA at room temperature but less than those achievable with CO PERCA.

The linear range observed is consistent with box model simulations, in particular when wall loss reactions are taken into account (Fig. S6 in the Supplement).

\subsubsection{Dependence of chain lengths on inlet temperature}

Next, we investigated the temperature dependence of the TDPERCA-CRDS signal when sampling photochemically generated PNA at constant RH and PNA mixing ratio. Figure 11 shows such a temperature scan of $\sim 180$ pptv PNA (measured in parallel by CIMS). The non-amplified TD profile observed by TD-CRDS is superimposed for comparison.

A striking feature in Fig. 11 is the very large increase in the amplified $\mathrm{NO}_{2}$ signal observed at temperatures above $\sim 150{ }^{\circ} \mathrm{C}$. This is an artifact that arises from $\mathrm{O}_{3}$ coemitted by the photochemical source and is commented on further in Sect. 3.6.1.

It is obvious from Fig. 11 that the amplification factor is strongly dependent on temperature: even though PNA fully dissociates at temperatures $>\sim 90^{\circ} \mathrm{C}$ in our inlets (Fig. 4), 
the amplified signal increases by $\sim 60 \%$ in the region from 90 to $135^{\circ} \mathrm{C}$ (Fig. 11, insert), corresponding to amplification factors of $\sim 15$ and $\sim 22$, respectively. This increase is qualitatively consistent (if extrapolated) with the higher amplification factor observed with PAN or PPN at $250^{\circ} \mathrm{C}$.

Box model simulations using only gas-phase chemistry from the MCM V3.3.1 (Fig. S3 in the Supplement) show that the $\mathrm{CL}$ is expected to decrease with increasing temperature, opposite to what is observed. This occurs in the model because the chain-carrying reactions of $\mathrm{HO}_{2}$ and $\mathrm{RO}_{2}$ with $\mathrm{NO}$ (e.g., Reaction R3, Table 3) have negative activation energies and are hence slower at higher temperatures, yielding a lower $\mathrm{CL}$ at higher temperature. This is partially offset when the chemistry of $\mathrm{HO}_{2} \cdot \mathrm{H}_{2} \mathrm{O}$ is added to the mechanism (Figs. S4 and S5 in the Supplement) but does not suffice to achieve a higher $\mathrm{CL}$ at higher temperature; the latter is only predicted by the box model simulations if much lower wall loss reactivity of $\mathrm{OH}$ and $\mathrm{HO}_{2}$ is assumed (see $\mathrm{S} 1.3$ and $\mathrm{S} 1.4$ in the Supplement).

\subsection{Interferences}

\subsubsection{Interference from $\mathrm{O}_{3}$ in the measurement of $\Sigma$ PAN at $250^{\circ} \mathrm{C}$}

When sampling ambient air (data not shown) or when sampling photochemically generated PNA (Fig. 11) the amplified $\mathrm{NO}_{2}$ increases sharply at PERCA inlet temperatures above $\sim 150^{\circ} \mathrm{C}$. These observations can be rationalized by thermal decomposition of $\mathrm{O}_{3}$. Even though only a small fraction of $\mathrm{O}_{3}$ dissociates to $\mathrm{O}_{2}+\mathrm{O}$ at $\sim 150^{\circ} \mathrm{C}$ in the TD inlet ( $\sim 0.1 \%$; Fig. 5; Jones and Davidson, 1962; Heimerl and Coffee, 1979), a comparatively large signal is generated because the $\mathrm{O}$ atom reacts with $\mathrm{C}_{2} \mathrm{H}_{6}$ to form two radicals, $\mathrm{OH}$ and $\mathrm{C}_{2} \mathrm{H}_{5}$ (Baulch et al., 1994). This reaction is competitive in the PERCA inlet (compared to reaction of $\mathrm{O}$ with $\mathrm{O}_{2}$ ) because of the high $\mathrm{C}_{2} \mathrm{H}_{6}$ concentration $(1.7 \%)$ : the lifetime of $\mathrm{O}$ with respect to reaction with $\mathrm{C}_{2} \mathrm{H}_{6}$ is $\sim 0.34 \mathrm{~ms}$, which is of similar magnitude as the expected lifetime of $\mathrm{O}$ with respect to reaction with $\mathrm{O}_{2}$ of $\sim 0.15 \mathrm{~ms}$ (Hippler et al., 1990).

We considered an alternate inlet configuration in which the inlet length between the NO and ethane addition points is increased to allow for sufficient residence time completely titrate $\mathrm{O}_{3}$ with the added NO. However, at the optimum NO mixing ratio for PERCA, the $1 / e$ lifetime of $\mathrm{O}_{3}$ is $\sim 6 \mathrm{~s}$, making this approach unfeasible.

Hence, if $\mathrm{O}_{3}$ is sampled with an ethane-based TD-PERCA instrument heated above $150^{\circ} \mathrm{C}$, radicals are generated that are amplified by PERCA. Since $\mathrm{O}_{3}$ is typically present at mixing ratios in the tens of ppbv in ambient air, quantification of $\Sigma$ PAN with an ethane-based TD-PERCA-CRDS would be challenging. In contrast, TD-PERCA instruments using $\mathrm{CO}$ will not have this limitation, as $\mathrm{CO}$ reacts with $\mathrm{O}$ to $\mathrm{CO}_{2}$ and would not generate $\mathrm{RO}_{x}$ radicals.

\subsubsection{Interference from peroxyacetic acid in the measurement of $\Sigma \mathrm{PAN}$ at $250^{\circ} \mathrm{C}$}

In a previous paper (Taha et al., 2018), we reported interference from peroxyacetic acid (PAA) when the inlet was operated at $250^{\circ} \mathrm{C}$. However, the mixing ratios delivered on those experiments were well above what is expected in ambient air. Further, it is unclear what fraction of PAA dissociates at $250^{\circ} \mathrm{C}$, since the Arrhenius parameters for TD of PAA are uncertain (Table 4). Regardless of whose Arrhenius parameters are assumed, the temperature needed to dissociate $0.1 \%$ of PAA is greater than that needed to dissociate $99.9 \%$ of PAN (Table 4). In ambient air, PAA is present at concentrations of up to 1 order of magnitude greater than that of PAN (Phillips et al., 2013). We estimate that under typical conditions, the interference from PAA dissociation is $<1 \%$ and likely be completely prevented if the inlet is operated at a temperature below $250^{\circ} \mathrm{C}$.

\subsubsection{Interference from $\Sigma P A N$ in the measurement of $\Sigma P N$ at $95-110{ }^{\circ} \mathrm{C}$}

A temperature of $95^{\circ} \mathrm{C}\left(110^{\circ} \mathrm{C}\right)$ is required to dissociate $>90 \%$ (>99.9\%) of PNA in the TD-PERCA inlet; at these temperatures, $\sim 12 \%(\sim 39 \%)$ of PAN dissociates (Fig. 4). Since [PAN] $>$ [PNA] (Table 1) and hence $\Sigma$ PAN $>\Sigma$ PN in most environments, the contribution of $\Sigma$ PAN to the $\Sigma$ PN signal in ambient air is substantial (and likely also variable given the slope of the PAN TD curve in this region). Hence, measurement of $\Sigma$ PN in ambient air by TD-PERCA-CRDS with a single channel relative to an $\mathrm{NO}_{2}$ background measurement is unfeasible.

\subsection{Differential temperature TD-PERCA-CRDS for measurement of $\Sigma$ PN and $\Sigma$ PAN}

\subsubsection{Synthetic air mixtures}

To overcome the limitations outlined in Sect. 3.6, a multichannel, differential temperature approach was used. Here, two channels were operated at constant temperatures set in the 60 to $110^{\circ} \mathrm{C}$ range to avoid the interference from $\mathrm{O}_{3}$ dissociation and ensure that response for $\Sigma$ PAN remains linear (by dissociating only a fraction of its concentration). Since the amount of $\mathrm{NO}_{2}$ generated by TD-PERCA is a function of temperature and radical chain length $\left(\mathrm{CL}_{T}\right)$ as well as a fraction dissociated $\left(F_{T}\right)$ of PNA and $\Sigma$ PAN, the responses in the two PERCA channels operated at different temperatures, $\mathrm{T} 1$ and $\mathrm{T} 2$, are

$$
\begin{aligned}
{\left[\mathrm{NO}_{2}\right]_{\mathrm{T} 1} } & =\mathrm{CL}_{\mathrm{T} 1} \times F_{\mathrm{PAN}, \mathrm{T} 1} \times[\Sigma \mathrm{PAN}]+\mathrm{CL}_{\mathrm{T} 1} \times F_{\mathrm{PNA}, \mathrm{T} 1} \\
& \times[\Sigma \mathrm{PN}]+\left[\mathrm{NO}_{2}\right]_{\mathrm{ref}}, \\
{\left[\mathrm{NO}_{2}\right]_{\mathrm{T} 2} } & =\mathrm{CL}_{\mathrm{T} 2} \times F_{\mathrm{PAN}, \mathrm{T} 2} \times[\Sigma \mathrm{PAN}]+\mathrm{CL}_{\mathrm{T} 2} \times F_{\mathrm{PNA}, \mathrm{T} 2} \\
& \times[\Sigma \mathrm{PN}]+\left[\mathrm{NO}_{2}\right]_{\mathrm{ref}} .
\end{aligned}
$$


Table 5. Products of CL and $F$ for PNA and PAN at 110,80 , and $60^{\circ} \mathrm{C}(\mathrm{RH}=34 \%)$.

\begin{tabular}{lrrr}
\hline & $\mathrm{CL}_{110^{\circ} \mathrm{C}} \times F_{110{ }^{\circ} \mathrm{C}}$ & $\mathrm{CL}_{80{ }^{\circ} \mathrm{C}} \times F_{80}{ }^{\circ} \mathrm{C}$ & $\mathrm{CL}_{60}{ }^{\circ} \mathrm{C} \times F_{60}{ }^{\circ} \mathrm{C}$ \\
\hline PNA & $41.8 \pm 0.2$ & $39.5 \pm 0.2$ & $31.9 \pm 0.1$ \\
LPAN & $10 \pm 1$ & $7.6 \pm 0.9$ & $1.2 \pm 0.2$ \\
\hline
\end{tabular}

Table 6. Statistics (average \pm 1 standard deviation) of the $1 \mathrm{~s}$ data shown in Fig. 12 .

\begin{tabular}{lrrr|rrr}
\hline & \multicolumn{3}{c|}{ PNA (pptv) } & \multicolumn{3}{c}{ PAN (pptv) } \\
\cline { 2 - 7 } Time period & $\mathrm{T} 1=110^{\circ} \mathrm{C}$ & $\mathrm{T} 1=110^{\circ} \mathrm{C}$ & $\mathrm{T} 1=80^{\circ} \mathrm{C}$ & $\mathrm{T} 1=110^{\circ} \mathrm{C}$ & $\mathrm{T} 1=110^{\circ} \mathrm{C}$ & $\mathrm{T} 1=80^{\circ} \mathrm{C}$ \\
$\mathrm{T} 2=60^{\circ} \mathrm{C}$ & $\mathrm{T} 2=80^{\circ} \mathrm{C}$ & $\mathrm{T} 2=60^{\circ} \mathrm{C}$ & $\mathrm{T} 2=60^{\circ} \mathrm{C}$ & $\mathrm{T} 2=80^{\circ} \mathrm{C}$ & $\mathrm{T} 2=60^{\circ} \mathrm{C}$ \\
\hline 21:48:45-21:49:15 & $266 \pm 4$ & $254 \pm 17$ & $267 \pm 4$ & $447 \pm 26$ & $495 \pm 75$ & $430 \pm 31$ \\
$21: 51: 15-21: 52: 45$ & $261 \pm 5$ & $258 \pm 14$ & $261 \pm 6$ & $480 \pm 32$ & $491 \pm 68$ & $476 \pm 38$ \\
\hline
\end{tabular}

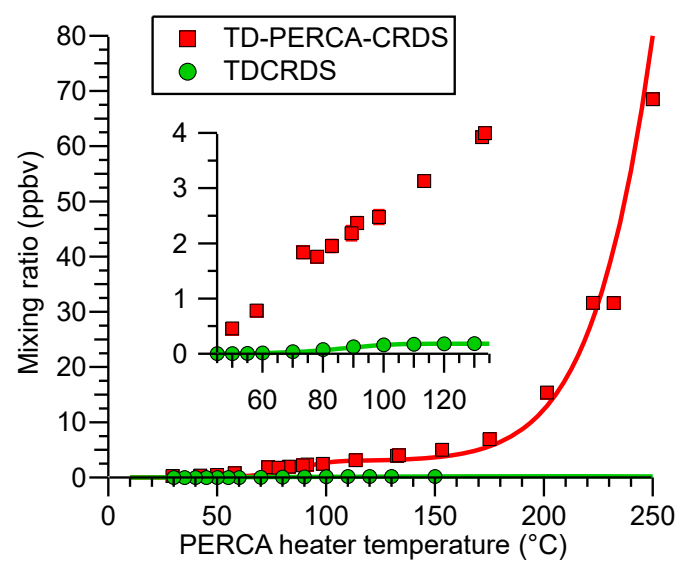

Figure 11. Amplification of photochemically generated PNA (red) as a function of PERCA heater temperature $(\mathrm{RH}=24 \%)$. Simultaneous quantification by CIMS and UV absorption showed that the gas stream contained $180 \pm 28$ pptv PNA and $3.5 \pm 0.2$ ppbv $\mathrm{O}_{3}$. The non-amplified TD-CRDS signal (from Fig. 4), multiplied by 0.18 , is shown in green for comparison.

If the $\mathrm{CL}_{T}$ and $F_{T}$ values are measured at temperatures $\mathrm{T} 1$ and $\mathrm{T} 2$ independently (i.e., offline), and $\left[\mathrm{NO}_{2}\right]_{\mathrm{ref}}$ is quantified in an unheated, parallel reference channel, the mixing ratios of $\Sigma \mathrm{PN}$ and $\Sigma \mathrm{PAN}$ can be calculated by rearranging Eq. (1a) and (1b):

$$
\begin{aligned}
& {[\Sigma \mathrm{PAN}]=} \\
& \frac{\left(\left[\mathrm{NO}_{2}\right]_{\mathrm{T} 1}-\left[\mathrm{NO}_{2}\right]_{\mathrm{ref}}\right) \times \mathrm{CL}_{\mathrm{T} 2} F_{\mathrm{PNA}, \mathrm{T} 2}-\left(\left[\mathrm{NO}_{2}\right]_{\mathrm{T} 2}-\left[\mathrm{NO}_{2}\right]_{\mathrm{ref}}\right) \times \mathrm{CL}_{\mathrm{T} 1} F_{\mathrm{PNA}, \mathrm{T} 1}}{\mathrm{CL}_{\mathrm{T} 2} F_{\mathrm{PNA}, \mathrm{T} 2} \times \mathrm{CL}_{\mathrm{T} 1} F_{\mathrm{PAN}, \mathrm{T} 1}-\mathrm{CL}_{\mathrm{T} 2} F_{\mathrm{PAN}, \mathrm{T} 2} \times \mathrm{CL}_{\mathrm{T} 1} F_{\mathrm{PNA}, \mathrm{T} 1}} \\
& {[\Sigma \mathrm{PN}]=\frac{\left(\left[\mathrm{NO}_{2}\right]_{\mathrm{T} 2}-\left[\mathrm{NO}_{2}\right]_{\mathrm{ref}}\right)-\mathrm{CL}_{\mathrm{T} 2 F_{\mathrm{PAN}, \mathrm{T} 2} \times[\Sigma \mathrm{PAN}]}}{\mathrm{CL}_{\mathrm{T} 2} F_{\mathrm{PNA}, \mathrm{T} 2}}}
\end{aligned}
$$

A time series demonstrating this approach using the fourchannel setup is presented in Fig. 12a. Here, a constant mixing ratio of PNA (along with $\mathrm{NO}_{2}$ and $\mathrm{O}_{3}$ from the photolysis source) was added to the inlet between 21:44 and 21:55.

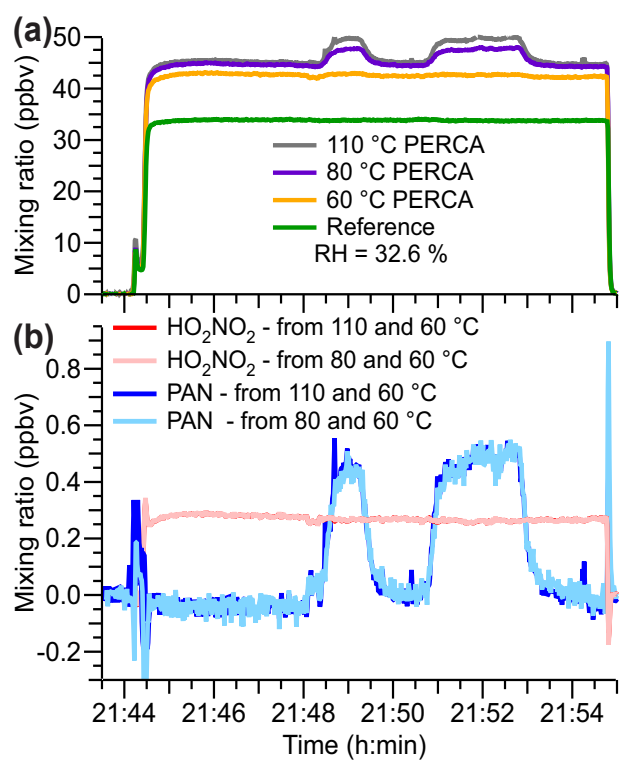

Figure 12. Demonstration of differential temperature TD-PERCACRDS. (a) Time series of $\mathrm{NO}_{2}$ mixing ratios observed by an unheated reference channel and three TD-PERCA channels operated at 60,80 , and $110^{\circ} \mathrm{C}$, respectively. PNA was sampled from 21:44:30 to 21:54:45, and PAN was added at $\sim 21: 49$ and $\sim 21: 52$. (b) Mixing ratios of PAN and PNA calculated from (a).

At 21:48:30 and at 21:50:45, PAN was added via the GC pre-column. The product of CL and $F$ for PAN and PNA at 110,80 , and $60^{\circ} \mathrm{C}$ was determined offline and summarized in Table 5, assumed to be the same for all $\Sigma$ PN and $\Sigma$ PAN species.

The time series of PNA and PAN mixing ratios derived from Eq. (2a) and (2b) are presented in Fig. 12b. Consistent results were obtained independent of which pair of channels was used in the calculations (Table 6). 
Table 7. Statistics (average \pm 1 standard deviation) of the $1 \mathrm{~s}$ data of laboratory air (first time period), laboratory air spiked with $\sim 260$ pptv PNA (second period), and laboratory air spiked with 260 pptv PNA and $~ 480$ pptv PAN (third period).

\begin{tabular}{lrrr|rrr}
\hline & \multicolumn{3}{c|}{$\Sigma \mathrm{PN}(\mathrm{ppbv})$} & \multicolumn{3}{c}{$\Sigma$ PAN (ppbv) } \\
\cline { 2 - 7 } Time period & $\mathrm{T} 1=110^{\circ} \mathrm{C}$ & $\mathrm{T} 1=110^{\circ} \mathrm{C}$ & $\mathrm{T} 1=80^{\circ} \mathrm{C}$ & $\mathrm{T} 1=110^{\circ} \mathrm{C}$ & $\mathrm{T} 1=110^{\circ} \mathrm{C}$ & $\mathrm{T} 1=80^{\circ} \mathrm{C}$ \\
& $\mathrm{T} 2=60^{\circ} \mathrm{C}$ & $\mathrm{T} 2=80^{\circ} \mathrm{C}$ & $\mathrm{T} 2=60^{\circ} \mathrm{C}$ & $\mathrm{T} 2=60^{\circ} \mathrm{C}$ & $\mathrm{T} 2=80^{\circ} \mathrm{C}$ & $\mathrm{T} 2=60^{\circ} \mathrm{C}$ \\
\hline Room air & $-0.08 \pm 0.01$ & $-0.29 \pm 0.03$ & $-0.068 \pm 0.004$ & $4.21 \pm 0.04$ & $5.1 \pm 0.1$ & $3.89 \pm 0.03$ \\
Room air + PNA & $0.19 \pm 0.01$ & $-0.03 \pm 0.02$ & $0.20 \pm 0.01$ & $3.50 \pm 0.03$ & $4.4 \pm 0.1$ & $3.17 \pm 0.04$ \\
$\Delta(\Sigma$ PN) & $0.27 \pm 0.01$ & $0.26 \pm 0.04$ & $0.27 \pm 0.01$ & $\mathrm{n} / \mathrm{a}$ & $\mathrm{n} / \mathrm{a}$ & $\mathrm{n} / \mathrm{a}$ \\
Room air + PNA + PAN & $0.19 \pm 0.01$ & $-0.02 \pm 0.02$ & $0.20 \pm 0.01$ & $3.99 \pm 0.04$ & $4.8 \pm 0.1$ & $3.70 \pm 0.03$ \\
$\Delta(\Sigma$ PAN) & $\mathrm{n} / \mathrm{a}$ & $\mathrm{n} / \mathrm{a}$ & $\mathrm{n} / \mathrm{a}$ & $0.49 \pm 0.04$ & $0.40 \pm 0.14$ & $0.52 \pm 0.05$ \\
\hline
\end{tabular}

$\mathrm{n} / \mathrm{a}$ indicates not applicable.

\subsubsection{Laboratory air}

The differential temperature TD-PERCA-CRDS was then used to sample and determine $\Sigma \mathrm{PN}$ and $\Sigma$ PAN in laboratory air. The calibration parameters summarized in Table 5 were used since they were determined with scrubbed air, which has the same RH as the air intake (i.e., the laboratory). The results are summarized in Table 7.

The calculated room air $\Sigma \mathrm{PN}$ values mixing ratios are negative (i.e., not physically possible). In contrast, the $\Sigma$ PAN mixing ratios are unreasonably large as we have never observed similarly high mixing ratios in our laboratory by GC, TD-CRDS, or CIMS. Taken together, these observations suggest that there is a species (or several) that dissociates in the $\mathrm{TD}$ inlet and generates $\mathrm{RO}_{x}$ radicals or, perhaps, atomic oxygen other than $\Sigma$ PAN. These unknown interfering species seem to have different TD profiles than PAN and PNA as the differential response differs when different pairs of channels are used in the calculation. Furthermore, the response to the unknown species is more prominent when the hottest $\left(110^{\circ} \mathrm{C}\right)$ channel is used in the calculation.

When $\sim 260$ pptv of PNA and $\sim 480$ pptv PAN (using the same setup as for Fig. 12 and Table 6) were added to the sampled laboratory air, the responses (i.e., $\Delta(\Sigma \mathrm{PN})$ and $\Delta(\Sigma P A N)$ are consistent in all channels, which suggests that the chain lengths and dissociated fractions had not changed. This observation corroborates that the ethane-based TD-PERCA-CRDS in reality quantifies $\Sigma P^{*} N^{*}$, which includes PAN, PPN, etc. plus one or more unidentified species. In Sect. 4, we speculate as to the potential identity of the interfering species.

\subsection{Figures of merit}

The ability of TD-PERCA-CRDS to detect radicals is limited by the instrument's ability to detect differences in $\mathrm{NO}_{2}$ concentration after amplification, calculated using (Brown et al., 2002)

$\left[\mathrm{NO}_{2}\right]_{\min }=\frac{R_{L}}{c \sigma_{\mathrm{NO}_{2}}}\left(\frac{\Delta \tau_{\min }}{\tau_{0}^{2}}\right)$
Here, $\left[\mathrm{NO}_{2}\right]_{\min }$ is the smallest $\mathrm{NO}_{2}$ concentration that can be detected, $\Delta \tau_{\min }$ is the smallest measurable difference between ring-down time constants in the presence $(\tau)$ and absence $\left(\tau_{0}\right)$ of $\mathrm{NO}_{2}, c$ is the speed of light, $\sigma_{\mathrm{NO}_{2}}$ is the $\mathrm{NO}_{2}$ absorption cross section at $405 \mathrm{~nm}\left(6.1 \times 10^{19} \mathrm{~cm}^{2}\right.$ molecule $^{-1}$, Paul and Osthoff, 2010), and $R_{L}$ is a correction factor. At the $1 \sigma$ level, $\Delta \tau_{\min }$ is approximately (Brown et al., 2002)

$\Delta \tau_{\min }=\sqrt{ } 2 \times \sigma\left(\tau_{0}\right)$.

The precision of the $\mathrm{NO}_{2}$ measurement (and hence the limit of detection, LOD) varied slightly between detection channels and from day to day. Typically, when sampling zero air, the LOD for $\mathrm{NO}_{2}$ was $\sim 100 \operatorname{pptv}(1 \mathrm{~s}, 2 \sigma)$. In the presence of $\mathrm{NO}$ and ethane reagent gases, the LOD was larger, typically $\sim 174$ pptv $(1 \mathrm{~s}, 2 \sigma)$.

Employing the dual-channel TD-PERCA-CRDS with the PERCA heater at $250^{\circ} \mathrm{C}$, a CL of 69 factored in, and in the absence of $\mathrm{NO}_{2}$, the $(1 \mathrm{~s}, 2 \sigma)$ LOD for $\Sigma \mathrm{PAN}^{*}$ (calculated on the basis of observed precision after subtraction of the reference channel signal, multiplying by $2 \sqrt{ } 2$, and dividing this precision by the CL) was $2.6 \mathrm{pptv}$. At an inlet temperature of $120^{\circ} \mathrm{C}$ and with a CL of 26 , the LOD for PNA was 6.8 pptv. When averaging for $90 \mathrm{~s}$, the minimum of an Allan variance plot (Fig. 7 of Paul and Osthoff, 2010), the LOD improved to $17 \mathrm{pptv}$ for $\mathrm{NO}_{2}, 0.26 \mathrm{pptv}$ for $\Sigma \mathrm{PAN}{ }^{*}$, and $0.66 \mathrm{pptv}$ for PNA. Under field conditions, where $\mathrm{NO}, \mathrm{NO}_{2}$, and $\mathrm{O}_{3}$ concentration vary, the LOD is expected to be higher, though this was not evaluated in this work.

The accuracy of TD-PERCA-CRDS is limited by uncertainties in CL ( $\pm 7 \%$ for dry air) and variability in the response to different type of peroxy radicals $( \pm 9 \%$ ) (Wood et al., 2016), and of the $\mathrm{NO}_{2}$ measurement ( $\left.\pm 4 \%\right)$, which is dominated by uncertainties in the absorption cross section and $R_{L}$ (Paul and Osthoff, 2010). Adding these in quadrature gives a combined uncertainty of $\pm 12 \%$ for dry air.

An additional uncertainty factor for the differential temperature TD-PERCA-CRDS is the uncertainty in $F_{T}$. The chambers are operated at temperatures where $F_{T}$ is highly sensitive to temperature (Fig. 4). Judging from the scatter 
observed (for example, in Table 6), we estimate that an additional $\pm 5 \%$ random error is introduced, raising the combined measurement uncertainty to $\pm 13 \%$. Not included in this estimate are systematic errors that might arise from the unknown and potentially variable TD profile of the interferences included in $\Sigma$ PAN*.

\section{Discussion}

The main goal of this work was to evaluate the feasibility of using ethane-based TD-PERCA to quantify $\Sigma$ PN and $\Sigma$ PAN in ambient air. This work has identified several stumbling blocks that on aggregate insinuate that such a measurement would be difficult and error-prone in practice.

On the one hand, the ethane-based TD-PERCA-CRDS has demonstrated great LODs $\left(<1\right.$ pptv for $\Sigma \mathrm{PAN}^{*}$ and PNA). This constitutes a considerable improvement compared to our previous generation TD-CRDS, whose LOD was in the hundreds of pptv (Paul and Osthoff, 2010), and represents the first optical absorption measurement of PNA at concentration levels of the same magnitude as found in ambient air (Table 1). In addition, the measurement can tolerate a large $\mathrm{NO}_{2}$ background through selective amplification of the desired signal: in Fig. 12, for example, the $\mathrm{NO}_{2}$ background was $>30 \mathrm{ppbv}$, yet PNA and PAN were quantified with a $1 \mathrm{~s} \sigma$ precision of $<6$ and $<40 \mathrm{pptv}$, respectively (Table 6 ). Moreover, the sensitivity of the ethane-based TD-PERCA is better than the room temperature measurement of $\mathrm{RO}_{x}$ radicals (1.6 pptv; $90 \mathrm{~s}, 2 \sigma$ ) (Wood et al., 2016), mainly because of the greater amplification $(\sim 69$ vs. $\sim 25)$ and in spite of the CAPS sensor being slightly more sensitive to $\mathrm{NO}_{2}$ than our CRDS. Furthermore, the instrument's sensitivity is comparable to (or better than) what is achievable with commonly used GC and CIMS methods. For example, at an inline temperature of $120^{\circ} \mathrm{C}$, the sensitivity of TD-PERCA-CRDS for PNA was of the same order of magnitude as our CIMS at its non-specific ion at $m / z 62$ and the optimized CIMS recently described by D. X. Chen et al. (2017).

The TD-PERCA-CRDS owes its good sensitivity to its high CL, which increases with temperature. Our attempts to rationalize the temperature through model simulations (see the Supplement) were limited because models simulating PERCA need to take wall loss rates into account and are generally poor predictors of experimental chain lengths. From a gas-phase kinetics perspective, reactions of $\mathrm{HO}_{2}$ and $\mathrm{RO}_{2}$ with NO (e.g., Reaction R3, Table 3) have a negative activation energy and are thus expected to slow down at higher temperatures, decreasing turnover rates and the CL. However, the $\mathrm{RH}$ dependence is reduced by heating, in part because one of the radical chain-terminating reaction, $\mathrm{HO}_{2}+\mathrm{NO} \rightarrow \mathrm{HNO}_{3}$, proceeds via a water adduct $\left(\mathrm{HO}_{2} \cdot \mathrm{H}_{2} \mathrm{O}\right)$ (Butkovskaya et al., 2007, 2009). The temperatures within the PERCA reaction heater are sufficiently elevated to dissociate this intermediate, shutting down this radical sink reaction. In addi- tion, the elevated temperatures inside the reactor may lessen reactions at the reactor inner wall surfaces (by driving off adsorbed water molecules, for example) though we lack direct evidence for this happening.

On the other hand, the TD-PERCA-CRDS method has several drawbacks, some of which still need to be overcome to make ambient measurements a reality.

The first challenge is posed by the TD profiles of PAN and PNA (Fig. 4) which are not completely separated. This overlap is particularly problematic in ambient air because the signal generated by the typically much smaller PNA concentrations could be overshadowed by a much larger $\Sigma$ PAN signal. In this work, the overlap of the TD profiles of PNA and PAN (and the rather limited dynamic range of $<500$ pptv) was overcome by the differential temperature-linear combination method (Sect. 3.7) in which $\Sigma$ PAN was only partially dissociated and PNA close to completely dissociated.

A complication is that methyl and ethyl peroxy nitrate have TD profiles that are similar, but not identical, to that of PNA; these molecules dissociate at lower temperatures than PNA (Table 4). This does not matter if the TD-PERCA inlets are operated at temperatures at which all three molecules are fully dissociated (or nearly so) as in this work.

The differential temperature approach has the additional advantage of avoiding the $\mathrm{O}_{3}$ interference that occurs above $150^{\circ} \mathrm{C}$, which would otherwise have been a serious issue because of the typically much larger $\mathrm{O}_{3}$ than PAN or PNA concentrations in ambient air, and it gave consistent results in synthesized air mixtures and room air.

A second drawback of TD-PERCA is the RH-dependent $\mathrm{CL}$, which necessitates frequent calibrations to determine $\mathrm{CL} \times F$ at each channel's temperature, though this could in principle be straightforward with photochemical sources of PNA and PAN and automated switching. At the same time, frequent calibrations of $\mathrm{CL}$ and $F$ would relax the need to carefully match the responses in each of the TD channels, which is a requirement in conventional TD instruments.

The third and most substantial drawback are the interferences. The $\mathrm{O}_{3}$ interference is easily avoided by switching the instrument from ethane to $\mathrm{CO}$ operation. With $\mathrm{CO}$, any $\mathrm{O}$ generated from $\mathrm{O}_{3}$ dissociation would react to form $\mathrm{CO}_{2}$ and be of no further consequence. However, CO-PERCA is somewhat unappealing because of CO's high toxicity and lack of smell, making its use impractical and impermissible in some university laboratories due to legitimate safety concerns. Mihele and Hastie (2000) used PAN as a radical source by heating a short section of the inlet of their CO-PERCA to $200^{\circ} \mathrm{C}$ and found the $\mathrm{CL}$ to be the same as other radical sources (which included passing $\mathrm{H}_{2}$ past a heated wire and a $\mathrm{Cl}_{2}$ photolysis source), which suggests that the $\mathrm{CL}$ in a $\mathrm{CO}-$ based PERCA is less dependent on temperature than with an ethane-based PERCA, which would be another advantage of CO-based PERCA.

The unknown interference observed in laboratory air is by far the biggest hurdle. We do not know the identity of the 
molecule or class of molecules interfering, and if the interference is present in ambient air, away from anthropogenic sources, or found only within a chemistry laboratory. We previously reported (Taha et al., 2018) that the ethane-based TD-PERCA-CRDS responds to peroxide explosives and also responds when sampling the head space above common skin cream and moisturizer products, which contain organosiloxanes. Organosiloxanes have become ubiquitous in the environment and have been found in indoor air in ppbv levels (Rücker and Kümmerer, 2015). Their barriers to dissociation have been reported (Davidson and Thompson, 1971) and are too large for decomposition to occur at the inlet temperatures used in this work. However, Kulyk et al. (2016) recently suggested that pyrolysis of certain polysiloxanes may occur at temperatures as low as $70^{\circ} \mathrm{C}$. Clearly, more work is needed to identify which molecules or class of molecules interferes in TD-PERCA-CRDS and are included in $\Sigma \mathrm{PAN}^{*}$. It is possible that the interfering species thermally dissociate(s) to release $\mathrm{O}$ atoms; if that is the case, this interference would not be present in a CO-based TD-PERCA. Hence, measurements using a CO-based TD-PERCA should be attempted. Furthermore, such measurements should be complemented by parallel measurements of PNA, PAN, and PPN by CIMS.

Data availability. The data used in this study are available from the corresponding author upon request (hosthoff@ucalgary.ca).

\section{The Supplement related to this article is available online at https://doi.org/10.5194/amt-11-4109-2018-supplement.}

Author contributions. YT and HO designed the experiments and carried them out. MS and YT constructed the single-channel inlet described in Sect. 2.1.1. FA synthesized the PAN and PPN samples (Sect. 2.2). XC and CY designed the setup for PAN delivery shown in Fig. 2. NG operated the CIMS and reduced the CIMS data. YT and $\mathrm{HO}$ prepared the manuscript with contributions from all coauthors.

Competing interests. The authors declare that they have no conflict of interest.

Acknowledgements. This work was made possible by the financial support of the National Science and Engineering Research Council of Canada (NSERC) in the form of a Discovery grant. The authors thank Ezra Wood for sharing a preprint version of the manuscript and useful discussions. Youssef M. Taha, Connie Z. Ye, and Natasha M. Garner acknowledge financial support from the NSERC Collaborative Research and Training Experience Program (CREATE) "Integrating Atmospheric Chemistry and Physics from Earth to Space" (IACPES) and QEII graduate scholarships.
Edited by: Mingjin Tang

Reviewed by: two anonymous referees

\section{References}

Abida, O., Mielke, L. H., and Osthoff, H. D.: Observation of gasphase peroxynitrous and peroxynitric acid during the photolysis of nitrate in acidified frozen solutions, Chem. Phys. Lett., 511, 187-192, https://doi.org/10.1016/j.cplett.2011.06.055, 2011.

Ahmadov, R., McKeen, S., Trainer, M., Banta, R., Brewer, A., Brown, S., Edwards, P. M., de Gouw, J. A., Frost, G. J., Gilman, J., Helmig, D., Johnson, B., Karion, A., Koss, A., Langford, A., Lerner, B., Olson, J., Oltmans, S., Peischl, J., Pétron, G., Pichugina, Y., Roberts, J. M., Ryerson, T., Schnell, R., Senff, C., Sweeney, C., Thompson, C., Veres, P. R., Warneke, C., Wild, R., Williams, E. J., Yuan, B., and Zamora, R.: Understanding high wintertime ozone pollution events in an oil- and natural gasproducing region of the western US, Atmos. Chem. Phys., 15, 411-429, https://doi.org/10.5194/acp-15-411-2015, 2015.

Atkinson, R., Baulch, D. L., Cox, R. A., Hampson, R. F., Kerr, J. A., Rossi, M. J., and Troe, J.: Evaluated kinetic, photochemical and heterogeneous data for atmospheric chemistry .5. IUPAC Subcommittee on Gas Kinetic Data Evaluation for Atmospheric Chemistry, J. Phys. Chem. Ref. Data, 26, 521-1011, https://doi.org/10.1063/1.556011, 1997.

Bates, D. R. and Nicolet, M.: The photochemistry of atmospheric water vapor, J. Geophys. Res., 55, 301-327, https://doi.org/10.1029/JZ055i003p00301, 1950.

Baulch, D. L., Cobos, C. J., Cox, R. A., Frank, P., Hayman, G., Just, T., Kerr, J. A., Murrells, T., Pilling, M. J., Troe, J., Walker, R. W., and Warnatz, J.: Summary table of evaluated kinetic data for combustion modeling: Supplement 1, Combustion and Flame, 98, 59-79, https://doi.org/10.1016/0010-2180(94)901988, 1994.

Blanchard, P., Shepson, P. B., Schiff, H. I., and Drummond, J. W.: Development of a gas-chromatograph for trace-level measurement of peroxyacetyl nitrate using chemical amplification, Anal. Chem., 65, 2472-2477, https://doi.org/10.1021/ac00066a012, 1993.

Brown, S. S., Stark, H., Ciciora, S. J., McLaughlin, R. J., and Ravishankara, A. R.: Simultaneous in situ detection of atmospheric $\mathrm{NO}_{3}$ and $\mathrm{N}_{2} \mathrm{O}_{5}$ via cavity ring-down spectroscopy, Rev. Sci. Instrum., 73, 3291-3301, https://doi.org/10.1063/1.1499214, 2002.

Butkovskaya, N., Kukui, A., and Le Bras, G.: $\mathrm{HNO}_{3}$ forming channel of the $\mathrm{HO}_{2}+\mathrm{NO}$ reaction as a function of pressure and temperature in the ranges of 72-600 Torr and 223-323 K, J. Phys. Chem. A, 111, 9047-9053, https://doi.org/10.1021/jp074117m, 2007.

Butkovskaya, N., Rayez, M. T., Rayez, J. C., Kukui, A., and Le Bras, G.: Water Vapor Effect on the $\mathrm{HNO}_{3}$ Yield in the $\mathrm{HO}_{2}+\mathrm{NO}$ Reaction: Experimental and Theoretical Evidence, J. Phys. Chem. A, 113, 11327-11342, https://doi.org/10.1021/jp811428p, 2009.

Cantrell, C. A., Stedman, D. H., and Wendel, G. J.: Measurement of atmospheric peroxy-radicals by chemical amplification, Anal Chem., 56, 1496-1502, https://doi.org/10.1021/ac00272a065, 1984. 
Cantrell, C. A., Shetter, R. E., and Calvert, J. G.: Dualinlet chemical amplifier for atmospheric peroxy radical measurements, Anal. Chem., 68, 4194-4199, https://doi.org/10.1021/ac960639e, 1996.

Chen, D. X., Huey, L. G., Tanner, D. J., Li, J. F., Ng, N. L., and Wang, Y. H.: Derivation of Hydroperoxyl Radical Levels at an Urban Site via Measurement of Pernitric Acid by Iodide Chemical Ionization Mass Spectrometry, Environ. Sci. Technol., 51, 3355-3363, https://doi.org/10.1021/acs.est.6b05169, 2017.

Chen, G., Davis, D., Crawford, J., Hutterli, L. M., Huey, L. G., Slusher, D., Mauldin, L., Eisele, F., Tanner, D., Dibb, J., Buhr, M., McConnell, J., Lefer, B., Shetter, R., Blake, D., Song, C. H., Lombardi, K., and Arnoldy, J.: A reassessment of $\mathrm{HO}_{x}$ South Pole chemistry based on observations recorded during ISCAT 2000, Atmos. Environ., 38, 5451-5461, https://doi.org/10.1016/j.atmosenv.2003.07.018, 2004.

Chen, J., Wu, H., Liu, A. W., Hu, S. M., and Zhang, J.: Field Measurement of $\mathrm{NO}_{2}$ and $\mathrm{RNO}_{2}$ by Two-Channel Thermal Dissociation Cavity Ring Down Spectrometer, Chin. J. Chem. Phys., 30, 493-498, https://doi.org/10.1063/16740068/30/cjcp1705084, 2017.

Crounse, J. D., Nielsen, L. B., Jorgensen, S., Kjaergaard, H. G., and Wennberg, P. O.: Autoxidation of Organic Compounds in the Atmosphere, J. Phys. Chem. Lett., 4, 3513-3520, https://doi.org/10.1021/jz4019207, 2013.

Davidson, I. M. T. and Thompson, J. F.: Dimethylsilanone from the pyrolysis of octamethylcyclotetrasiloxane, J. Chem. Soc. D, 251-252, https://doi.org/10.1039/c29710000251, 1971.

Davis, D., Chen, G., Buhr, M., Crawford, J., Lenschow, D., Lefer, B., Shetter, R., Eisele, F., Mauldin, L., and Hogan, A.: South Pole $\mathrm{NO}_{x}$ chemistry: an assessment of factors controlling variability and absolute levels, Atmos. Environ., 38, 5375-5388, https://doi.org/10.1016/j.atmosenv.2004.04.039, 2004.

Day, D. A., Wooldridge, P. J., Dillon, M. B., Thornton, J. A., and Cohen, R. C.: A thermal dissociation laser-induced fluorescence instrument for in situ detection of $\mathrm{NO}_{2}$, peroxy nitrates, alkyl nitrates, and $\mathrm{HNO}_{3}$, J. Geophys. Res., 107, 4046, https://doi.org/10.1029/2001JD000779, 2002.

Devush, S. S., Prisyazhnyuk, Z. P., and Kovalskaya, A. M.: Kinetics of the thermal gas-phase decomposition of C1-C4 organic peracids, Kinet. Catal., 24, 1098-1101, 1983.

Di Carlo, P., Aruffo, E., Busilacchio, M., Giammaria, F., DariSalisburgo, C., Biancofiore, F., Visconti, G., Lee, J., Moller, S., Reeves, C. E., Bauguitte, S., Forster, G., Jones, R. L., and Ouyang, B.: Aircraft based four-channel thermal dissociation laser induced fluorescence instrument for simultaneous measurements of $\mathrm{NO}_{2}$, total peroxy nitrate, total alkyl nitrate, and $\mathrm{HNO}_{3}$, Atmos. Meas. Tech., 6, 971-980, https://doi.org/10.5194/amt-6971-2013, 2013.

Dusanter, S., Vimal, D., Stevens, P. S., Volkamer, R., and Molina, L. T.: Measurements of $\mathrm{OH}$ and $\mathrm{HO} 2$ concentrations during the MCMA-2006 field campaign - Part 1: Deployment of the Indiana University laser-induced fluorescence instrument, Atmos. Chem. Phys., 9, 1665-1685, https://doi.org/10.5194/acp-9-16652009, 2009.

Edwards, G. D., Cantrell, C. A., Stephens, S., Hill, B., Goyea, O., Shetter, R. E., Mauldin, R. L., Kosciuch, E., Tanner, D. J., and Eisele, F. L.: Chemical ionization mass spectrometer instrument for the measurement of tro- pospheric $\mathrm{HO}_{2}$ and $\mathrm{RO}_{2}$, Anal. Chem., 75, 5317-5327, https://doi.org/10.1021/ac034402b, 2003.

Ehn, M., Thornton, J. A., Kleist, E., Sipila, M., Junninen, H., Pullinen, I., Springer, M., Rubach, F., Tillmann, R., Lee, B., Lopez-Hilfiker, F., Andres, S., Acir, I.-H., Rissanen, M., Jokinen, T., Schobesberger, S., Kangasluoma, J., Kontkanen, J., Nieminen, T., Kurten, T., Nielsen, L. B., Jorgensen, S., Kjaergaard, H. G., Canagaratna, M., Maso, M. D., Berndt, T., Petaja, T., Wahner, A., Kerminen, V.-M., Kulmala, M., Worsnop, D. R., Wildt, J., and Mentel, T. F.: A large source of lowvolatility secondary organic aerosol, Nature, 506, 476-479, https://doi.org/10.1038/nature13032, 2014.

Eisele, F., Davis, D. D., Helmig, D., Oltmans, S. J., Neff, W., Huey, G., Tanner, D., Chen, G., Crawford, J., Arimoto, R., Buhr, M., Mauldin, L., Hutterli, M., Dibb, J., Blake, D., Brooks, S. B., Johnson, B., Roberts, J. M., Wang, Y. H., Tan, D., and Flocke, F.: Antarctic Tropospheric Chemistry Investigation (ANTCI) 2003 overview, Atmos. Environ., 42, 2749-2761, https://doi.org/10.1016/j.atmosenv.2007.04.013, 2008.

Faloona, I. C., Tan, D., Lesher, R. L., Hazen, N. L., Frame, C. L., Simpas, J. B., Harder, H., Martinez, M., Di Carlo, P., Ren, X. R., and Brune, W. H.: A laser-induced fluorescence instrument for detecting tropospheric $\mathrm{OH}$ and $\mathrm{HO}_{2}$ : Characteristics and calibration, J. Atmos. Chem., 47, 139-167, https://doi.org/10.1023/B:JOCH.0000021036.53185.0e, 2004.

Fleming, Z. L., Monks, P. S., Rickard, A. R., Heard, D. E., Bloss, W. J., Seakins, P. W., Still, T. J., Sommariva, R., Pilling, M. J., Morgan, R., Green, T. J., Brough, N., Mills, G. P., Penkett, S. A., Lewis, A. C., Lee, J. D., Saiz-Lopez, A., and Plane, J. M. C.: Peroxy radical chemistry and the control of ozone photochemistry at Mace Head, Ireland during the summer of 2002, Atmos. Chem. Phys., 6, 2193-2214, https://doi.org/10.5194/acp-6-21932006, 2006.

Fuchs, H., Holland, F., and Hofzumahaus, A.: Measurement of tropospheric $\mathrm{RO}_{2}$ and $\mathrm{HO}_{2}$ radicals by a laser-induced fluorescence instrument, Rev. Sci. Instrum., 79, 084104-084112, https://doi.org/10.1063/1.2968712, 2008.

Fuchs, H., Dubé, W. P., Lerner, B. M., Wagner, N. L., Williams, E. J., and Brown, S. S.: A Sensitive and Versatile Detector for Atmospheric $\mathrm{NO}_{2}$ and $\mathrm{NO}_{x}$ Based on Blue Diode Laser Cavity Ring-Down Spectroscopy, Environ. Sci. Technol., 43, 78317836, https://doi.org/10.1021/es902067h, 2009.

Furgeson, A., Mielke, L. H., Paul, D., and Osthoff, H. D.: A photochemical source of peroxypropionic and peroxyisobutanoic nitric anhydride, Atmos. Environ., 45, 5025-5032, https://doi.org/10.1016/j.atmosenv.2011.03.072, 2011.

Green, T. J., Reeves, C. E., Fleming, Z. L., Brough, N., Rickard, A. R., Bandy, B. J., Monks, P. S., and Penkett, S. A.: An improved dual channel PERCA instrument for atmospheric measurements of peroxy radicals, J. Environ. Monit., 8, 530-536, https://doi.org/10.1039/B514630E, 2006.

Grosjean, D., Grosjean, E., and Williams, E. L.: Thermal decomposition of PAN, PPN and vinylPAN, J. Air Waste Manag. Assoc., 44, 391-396, https://doi.org/10.1080/1073161X.1994.10467260, 1994.

Hanke, M., Uecker, J., Reiner, T., and Arnold, F.: Atmospheric peroxy radicals: ROXMAS, a new mass-spectrometric methodology for speciated measurements of $\mathrm{HO}_{2}$ and Sigma 
$\mathrm{RO}_{2}$ and first results, Int. J. Mass Spectrom., 213, 91-99, https://doi.org/10.1016/s1387-3806(01)00548-6, 2002.

Hastie, D. R., Weissenmayer, M., Burrows, J. P., and Harris, G. W.: Calibrated chemical amplifier for atmospheric $\mathrm{RO}_{x}$ measurements, Anal. Chem., 63, 2048-2057, https://doi.org/10.1021/ac00018a029, 1991.

Heard, D. E.: Atmospheric field measurements of the hydroxyl radical using laser-induced fluorescence spectroscopy, Ann. Rev. Phys. Chem., 57, 191-216, https://doi.org/10.1146/annurev.physchem.57.032905.104516, 2006.

Heimerl, J. M. and Coffee, T. P.: The unimolecular ozone decomposition reaction, Combust. Flame, 35, 117-123, https://doi.org/10.1016/0010-2180(79)90015-4, 1979.

Hippler, H., Rahn, R., and Troe, J.: Temperature and pressure dependence of ozone formation rates in the range 11000 bar and 90-370 K, J. Chem. Phys., 93, 6560-6569, https://doi.org/10.1063/1.458972, 1990.

Hornbrook, R. S., Crawford, J. H., Edwards, G. D., Goyea, O., Mauldin Iii, R. L., Olson, J. S., and Cantrell, C. A.: Measurements of tropospheric $\mathrm{HO}_{2}$ and $\mathrm{RO}_{2}$ by oxygen dilution modulation and chemical ionization mass spectrometry, Atmos. Meas. Tech., 4, 735-756, https://doi.org/10.5194/amt-4735-2011, 2011.

Horstjann, M., Andres Hernandez, M. D., Nenakhov, V., Chrobry, A., and Burrows, J. P.: Peroxy radical detection for airborne atmospheric measurements using absorption spectroscopy of $\mathrm{NO}_{2}$, Atmos. Meas. Tech., 7, 1245-1257, https://doi.org/10.5194/amt7-1245-2014, 2014.

Jenkin, M. E., Saunders, S. M., and Pilling, M. J.: The tropospheric degradation of volatile organic compounds: a protocol for mechanism development, Atmos. Environ., 31, 81-104, https://doi.org/10.1016/S1352-2310(96)00105-7, 1997.

Jenkin, M. E., Wyche, K. P., Evans, C. J., Carr, T., Monks, P. S., Alfarra, M. R., Barley, M. H., McFiggans, G. B., Young, J. C., and Rickard, A. R.: Development and chamber evaluation of the MCM v3.2 degradation scheme for $\beta$-caryophyllene, Atmos. Chem. Phys., 12, 5275-5308, https://doi.org/10.5194/acp12-5275-2012, 2012.

Jones, A. E., Brough, N., Anderson, P. S., and Wolff, E. W.: $\mathrm{HO}_{2} \mathrm{NO}_{2}$ and $\mathrm{HNO}_{3}$ in the coastal Antarctic winter night: a "labin-the-field" experiment, Atmos. Chem. Phys., 14, 11843-11851, https://doi.org/10.5194/acp-14-11843-2014, 2014.

Jones, W. M. and Davidson, N.: The Thermal Decomposition of Ozone in a Shock Tube, J. Am. Chem. Soc., 84, 2868-2878, https://doi.org/10.1021/ja00874a005, 1962.

Kabir, M., Jagiella, S., and Zabel, F.: Thermal Stability of nAcyl Peroxynitrates, Internat. J. Chem. Kin., 46, 462-469, https://doi.org/10.1002/kin.20862, 2014.

Kanno, N., Tonokura, K., and Koshi, M.: Equilibrium constant of the $\mathrm{HO}_{2}-\mathrm{H}_{2} \mathrm{O}$ complex formation and kinetics of $\mathrm{HO}_{2}+\mathrm{HO}_{2}-$ $\mathrm{H}_{2} \mathrm{O}$ : Implications for tropospheric chemistry, J. Geophys. Res.Atmos., 111, D20312, https://doi.org/10.1029/2005jd006805, 2006.

Kim, S., Huey, L. G., Stickel, R. E., Tanner, D. J., Crawford, J. H., Olson, J. R., Chen, G., Brune, W. H., Ren, X., Lesher, R., Wooldridge, P. J., Bertram, T. H., Perring, A., Cohen, R. C., Lefer, B. L., Shetter, R. E., Avery, M., Diskin, G., and Sokolik, I.: Measurement of $\mathrm{HO}_{2} \mathrm{NO}_{2}$ in the free troposphere during the Intercontinental Chemical Transport ExperimentNorth America 2004, J. Geophys. Res.-Atmos., 112, D12S01, https://doi.org/10.1029/2006jd007676, 2007.

Kirchner, F. and Stockwell, W. R.: Effect of peroxy radical reactions on the predicted concentrations of ozone, nitrogenous compounds, and radicals, J. Geophys. Res.-Atmos., 101, 2100721022, https://doi.org/10.1029/96jd01519, 1996.

Kulyk, K., Zettergren, H., Gatchell, M., Alexander, J. D., Borysenko, M., Palianytsia, B., Larsson, M., and Kulik, T.: Dimethylsilanone Generation from Pyrolysis of Polysiloxanes Filled with Nanosized Silica and Ceria/Silica, Chem. Plus. Chem., 81, 1003 1013, https://doi.org/10.1002/cplu.201600229, 2016.

Lee, J. B., Yoon, J. S., Jung, K., Eom, S. W., Chae, Y. Z., Cho, S. J., Kim, S. D., Sohn, J. R., and Kim, K. H.: Peroxyacetyl nitrate (PAN) in the urban atmosphere, Chemosphere, 93, 1796-1803, https://doi.org/10.1016/j.chemosphere.2013.06.019, 2013.

Lee, L., Wooldridge, P. J., deGouw, J., Brown, S. S., Bates, T. S., Quinn, P. K., and Cohen, R. C.: Particulate organic nitrates observed in an oil and natural gas production region during wintertime, Atmos. Chem. Phys., 15, 9313-9325, https://doi.org/10.5194/acp-15-9313-2015, 2015.

Liu, Y. and Zhang, J.: Atmospheric Peroxy Radical Measurements Using Dual-Channel Chemical Amplification Cavity Ringdown Spectroscopy, Anal. Chem., 86, 5391-5398, https://doi.org/10.1021/ac5004689, 2014.

Mielke, L. H. and Osthoff, H. D.: On quantitative measurements of peroxycarboxylic nitric anhydride mixing ratios by thermal dissociation chemical ionization mass spectrometry, Int. J. Mass Spectrom., 310, 1-9, https://doi.org/10.1016/j.ijms.2011.10.005, 2012.

Mielke, L. H., Furgeson, A., and Osthoff, H. D.: Observation of $\mathrm{ClNO}_{2}$ in a mid-continental urban environment, Environ. Sci. Technol., 45, 8889-8896, https://doi.org/10.1021/es201955u, 2011.

Mihele, C. M. and Hastie, D. R.: The sensitivity of the radical amplifier to ambient water vapour, Geophys. Res. Lett., 25, 19111913, https://doi.org/10.1029/98g101432, 1998.

Mihele, C. M. and Hastie, D. R.: Optimized operation and calibration procedures for radical amplifiertype detectors, Journal Of Atmospheric And Oceanic Technology, 17, 788-794, https://doi.org/10.1175/15200426(2000)017<0788:OOACPF>2.0.CO;2, 2000.

Mihele, C. M., Mozurkewich, M., and Hastie, D. R.: Radical loss in a chain reaction of $\mathrm{CO}$ and $\mathrm{NO}$ in the presence of water: Implications for the radical amplifier and atmospheric chemistry, Internat. J. Chem. Kin., 31, 145-152, https://doi.org/10.1002/(sici)1097-4601(1999)31:2<145::aidkin7>3.0.co;2-m, 1999.

Mills, G. P., Sturges, W. T., Salmon, R. A., Bauguitte, S. J. B., Read, K. A., and Bandy, B. J.: Seasonal variation of peroxyacetylnitrate (PAN) in coastal Antarctica measured with a new instrument for the detection of sub-part per trillion mixing ratios of PAN, Atmos. Chem. Phys., 7, 4589-4599, https://doi.org/10.5194/acp-74589-2007, 2007.

Murphy, J. G., Thornton, J. A., Wooldridge, P. J., Day, D. A., Rosen, R. S., Cantrell, C., Shetter, R. E., Lefer, B., and Cohen, R. C.: Measurements of the sum of $\mathrm{HO}_{2} \mathrm{NO}_{2}$ and $\mathrm{CH}_{3} \mathrm{O}_{2} \mathrm{NO}_{2}$ in the remote troposphere, Atmos. Chem. Phys., 4, 377-384, https://doi.org/10.5194/acp-4-377-2004, 2004. 
Odame-Ankrah, C. A.: Improved detection instrument for nitrogen oxide species, Ph.D., Chemistry, University of Calgary, available at: http://hdl.handle.net/11023/2006, https://doi.org/10.5072/PRISM/26475, Calgary, 2015.

Odame-Ankrah, C. A. and Osthoff, H. D.: A compact diode laser cavity ring-down spectrometer for atmospheric measurements of $\mathrm{NO}_{3}$ and $\mathrm{N}_{2} \mathrm{O}_{5}$ with automated zeroing and calibration, Appl. Spectrosc., 65, 1260-1268, https://doi.org/10.1366/1106384, 2011.

Paul, D. and Osthoff, H. D.: Absolute Measurements of Total Peroxy Nitrate Mixing Ratios by Thermal Dissociation Blue Diode Laser Cavity Ring-Down Spectroscopy, Anal. Chem., 82, 66956703, https://doi.org/10.1021/ac101441z, 2010.

Paul, D., Furgeson, A., and Osthoff, H. D.: Measurements of total peroxy and alkyl nitrate abundances in laboratorygenerated gas samples by thermal dissociation cavity ring-down spectroscopy, Rev. Sci. Instrum., 80, 114101, https://doi.org/10.1063/1.3258204 2009.

Perez, I. M., Wooldridge, P. J., and Cohen, R. C.: Laboratory evaluation of a novel thermal dissociation chemiluminescence method for in situ detection of nitrous acid, Atmos. Environ., 41, 39934001, https://doi.org/10.1016/j.atmosenv.2007.01.060, 2007.

Phillips, G. J., Pouvesle, N., Thieser, J., Schuster, G., Axinte, R., Fischer, H., Williams, J., Lelieveld, J., and Crowley, J. N.: Peroxyacetyl nitrate (PAN) and peroxyacetic acid (PAA) measurements by iodide chemical ionisation mass spectrometry: first analysis of results in the boreal forest and implications for the measurement of PAN fluxes, Atmos. Chem. Phys., 13, 11291139, https://doi.org/10.5194/acp-13-1129-2013, 2013.

Portmann, R. W., Brown, S. S., Gierczak, T., Talukdar, R. K., Burkholder, J. B., and Ravishankara, A. R.: Role of nitrogen oxides in the stratosphere: A reevaluation based on laboratory studies, Geophys. Res. Lett., 26, 2387-2390, https://doi.org/10.1029/1999GL900499, 1999.

Roberts, J. M.: The atmospheric chemistry of organic nitrates, Atmos. Environ. A, 24, 243-287, https://doi.org/10.1016/09601686(90)90108-Y, 1990.

Roberts, J. M.: PAN and Related Compounds, in: Volatile Organic Compounds in the Atmosphere, edited by: Koppmann, R., Blackwell Publishing, Oxford, UK, 221-268, 2007.

Rollins, A. W., Smith, J. D., Wilson, K. R., and Cohen, R. C.: Real Time In Situ Detection of Organic Nitrates in Atmospheric Aerosols, Environ. Sci. Technol., 44, 5540-5545, https://doi.org/10.1021/es100926x, 2010.

Rücker, C. and Kümmerer, K.: Environmental Chemistry of Organosiloxanes, Chem. Rev., 115, 466-524, https://doi.org/10.1021/cr500319v, 2015.

Sadanaga, Y., Takaji, R., Ishiyama, A., Nakajima, K., Matsuki, A., and Bandow, H.: Thermal dissociation cavity attenuated phase shift spectroscopy for continuous measurement of total peroxy and organic nitrates in the clean atmosphere, Rev. Sci. Instrum., 87, 074102, https://doi.org/10.1063/1.4958167, 2016.

Sahetchian, K. A., Rigny, R., Tardieu de Maleissye, J., Batt, L., Anwar Khan, M., and Mathews, S.: The pyrolysis of organic hydroperoxides (ROOH), Symposium (International) on Combustion, 24, 637-643, https://doi.org/10.1016/S00820784(06)80078-0, 1992.

Sandu, A. and Sander, R.: Technical note: Simulating chemical systems in Fortran90 and Matlab with the Kinetic
PreProcessor KPP-2.1, Atmos. Chem. Phys., 6, 187-195, https://doi.org/10.5194/acp-6-187-2006, 2006.

Saunders, S. M., Jenkin, M. E., Derwent, R. G., and Pilling, M. J.: Protocol for the development of the Master Chemical Mechanism, MCM v3 (Part A): tropospheric degradation of nonaromatic volatile organic compounds, Atmos. Chem. Phys., 3, 161-180, https://doi.org/10.5194/acp-3-161-2003, 2003.

Schmidt, C. and Sehon, A. H.: The thermal decomposition of peracetic acid in the vapor phase, Canad. J. Chem., 41, 1819-1825, https://doi.org/10.1139/v63-261, 1963.

Singh, H. B., Herlth, D., Ohara, D., Zahnle, K., Bradshaw, J. D., Sandholm, S. T., Talbot, R., Crutzen, P. J., and Kanakidou, M.: Relationship of peroxyacetyl nitrate to active and total odd nitrogen at northern high-latitudes - influence of reservoir species on $\mathrm{NO}_{x}$ and $\mathrm{O}_{3}$, J. Geophys. Res.-Atmos., 97, 16523-16530, https://doi.org/10.1029/91jd00890, 1992.

Singh, H. B., Brune, W. H., Crawford, J. H., Jacob, D. J., and Russell, P. B.: Overview of the summer 2004 Intercontinental Chemical Transport Experiment-North America (INTEX-A), J. Geophys. Res.-Atmos., 111, D24S01, https://doi.org/10.1029/2006jd007905, 2006.

Slusher, D. L., Pitteri, S. J., Haman, B. J., Tanner, D. J., and Huey, L. G.: A chemical ionization technique for measurement of pernitric acid in the upper troposphere and the polar boundary layer, Geophys. Res. Lett., 28, 3875-3878, https://doi.org/10.1029/2001gl013443, 2001.

Slusher, D. L., Huey, L. G., Tanner, D. J., Flocke, F. M., and Roberts, J. M.: A thermal dissociation-chemical ionization mass spectrometry (TD-CIMS) technique for the simultaneous measurement of peroxyacyl nitrates and dinitrogen pentoxide, J. Geophys. Res., 109, D19315, https://doi.org/10.1029/2004JD004670, 2004.

Sobanski, N., Schuladen, J., Schuster, G., Lelieveld, J., and Crowley, J. N.: A five-channel cavity ring-down spectrometer for the detection of $\mathrm{NO}_{2}, \mathrm{NO}_{3}, \mathrm{~N}_{2} \mathrm{O}_{5}$, total peroxy nitrates and total alkyl nitrates, Atmos. Meas. Tech., 9, 5103-5118, https://doi.org/10.5194/amt-9-5103-2016, 2016.

Solomon, S.: Stratospheric ozone depletion: A review of concepts and history, Rev. Geophys., 37, 275-316, https://doi.org/10.1029/1999RG900008, 1999.

Spencer, K. M., McCabe, D. C., Crounse, J. D., Olson, J. R., Crawford, J. H., Weinheimer, A. J., Knapp, D. J., Montzka, D. D., Cantrell, C. A., Hornbrook, R. S., Mauldin, R. L., and Wennberg, P. O.: Inferring ozone production in an urban atmosphere using measurements of peroxynitric acid, Atmos. Chem. Phys., 9, 3697-3707, https://doi.org/10.5194/acp-9-3697-2009, 2009.

Stenke, A. and Grewe, V.: Simulation of stratospheric water vapor trends: impact on stratospheric ozone chemistry, Atmos. Chem. Phys., 5, 1257-1272, https://doi.org/10.5194/acp-5-1257-2005, 2005.

Taha, Y. M., Saowapon, M. T., and Osthoff, H. D.: Detection of triacetone triperoxide by thermal decomposition peroxy radical chemical amplification coupled to cavity ringdown spectroscopy, Anal. Bioanal. Chem., 410, 4203-4212, https://doi.org/10.1007/s00216-018-1072-0, 2018.

Thaler, R. D., Mielke, L. H., and Osthoff, H. D.: Quantification of Nitryl Chloride at Part Per Trillion Mixing Ratios by Thermal Dissociation Cavity Ring-Down Spectroscopy, Anal. Chem., 83, 2761-2766, https://doi.org/10.1021/ac200055z, 2011. 
Thieser, J., Schuster, G., Schuladen, J., Phillips, G. J., Reiffs, A., Parchatka, U., Pöhler, D., Lelieveld, J., and Crowley, J. N.: A two-channel thermal dissociation cavity ring-down spectrometer for the detection of ambient $\mathrm{NO}_{2}, \mathrm{RO}_{2} \mathrm{NO}_{2}$ and $\mathrm{RONO}_{2}$, Atmos. Meas. Tech., 9, 553-576, https://doi.org/10.5194/amt-9553-2016, 2016.

Tokarek, T. W., Huo, J. A., Odame-Ankrah, C. A., Hammoud, D., Taha, Y. M., and Osthoff, H. D.: A gas chromatograph for quantification of peroxycarboxylic nitric anhydrides calibrated by thermal dissociation cavity ring-down spectroscopy, Atmos. Meas. Tech., 7, 3263-3283, https://doi.org/10.5194/amt-7-32632014, 2014.

Tuazon, E. C., Winer, A. M., and Pitts, J. N.: Trace pollutant concentrations in a multiday smog episode in the California South Coast Air Basin by long path length Fourier transform infrared spectroscopy, Environ. Sci. Technol., 15, 1232-1237, https://doi.org/10.1021/es00092a014, 1981.

Veres, P. R., Roberts, J. M., Wild, R. J., Edwards, P. M., Brown, S. S., Bates, T. S., Quinn, P. K., Johnson, J. E., Zamora, R. J., and de Gouw, J.: Peroxynitric acid $\left(\mathrm{HO}_{2} \mathrm{NO}_{2}\right)$ measurements during the UBWOS 2013 and 2014 studies using iodide ion chemical ionization mass spectrometry, Atmos. Chem. Phys., 15, 81018114, https://doi.org/10.5194/acp-15-8101-2015, 2015.

Wild, R. J., Edwards, P. M., Dube, W. P., Baumann, K., Edgerton, E. S., Quinn, P. K., Roberts, J. M., Rollins, A. W., Veres, P. R., Warneke, C., Williams, E. J., Yuan, B., and Brown, S. S.: A Measurement of Total Reactive Nitrogen, $\mathrm{NO}_{y}$, together with $\mathrm{NO}_{2}$, $\mathrm{NO}$, and $\mathrm{O}_{3}$ via Cavity Ring-down Spectroscopy, Environ. Sci. Technol., 48, 9609-9615, https://doi.org/10.1021/es501896w, 2014.
Womack, C. C., Neuman, J. A., Veres, P. R., Eilerman, S. J., Brock, C. A., Decker, Z. C. J., Zarzana, K. J., Dube, W. P., Wild, R. J., Wooldridge, P. J., Cohen, R. C., and Brown, S. S.: Evaluation of the accuracy of thermal dissociation CRDS and LIF techniques for atmospheric measurement of reactive nitrogen species, Atmos. Meas. Tech., 10, 1911-1926, https://doi.org/10.5194/amt10-1911-2017, 2017.

Wood, E. C., Deming, B. L., and Kundu, S.: Ethane-Based Chemical Amplification Measurement Technique for Atmospheric Peroxy Radicals, Environ.Sci. Technol. Lett., 4, 15-19, https://doi.org/10.1021/acs.estlett.6b00438, 2016.

Wooldridge, P. J., Perring, A. E., Bertram, T. H., Flocke, F. M., Roberts, J. M., Singh, H. B., Huey, L. G., Thornton, J. A., Wolfe, G. M., Murphy, J. G., Fry, J. L., Rollins, A. W., LaFranchi, B. W., and Cohen, R. C.: Total Peroxy Nitrates ( $\Sigma$ PNs) in the atmosphere: the Thermal Dissociation-Laser Induced Fluorescence (TD-LIF) technique and comparisons to speciated PAN measurements, Atmos. Meas. Tech., 3, 593-607, https://doi.org/10.5194/amt-3-593-2010, 2010.

Zheng, W., Flocke, F. M., Tyndall, G. S., Swanson, A., Orlando, J. J., Roberts, J. M., Huey, L. G., and Tanner, D. J.: Characterization of a thermal decomposition chemical ionization mass spectrometer for the measurement of peroxy acyl nitrates (PANs) in the atmosphere, Atmos. Chem. Phys., 11, 6529-6547, https://doi.org/10.5194/acp-11-6529-2011, 2011.

Ziemann, P. J. and Atkinson, R.: Kinetics, products, and mechanisms of secondary organic aerosol formation, Chem. Soc. Rev., 41, 6582-6605, https://doi.org/10.1039/c2cs35122f, 2012. 